Geopolítica(s) Revista de estudios sobre espacio y poder ISSN: 2172-3958

https://dx.doi.org/10.5209/geop.64580

\title{
Fronteras ocultas en la zona gris europea
}

\author{
Miguel Borja Bernabé-Crespo ${ }^{1}$
}

Recibido: 4 de junio de 2019 / Aceptado: 19 de junio de 2020

Resumen. La llamada "zona gris europea" consiste en los espacios de transición entre el conflicto abierto y la paz, en la actualidad presentes en la frontera este de la Unión Europea. Se trata de la esfera de expansión de la UE y OTAN, que coincide con el espacio exsoviético europeo, del cual Moscú sigue ejerciendo una notable influencia. En un escenario de creciente tensión entre estos dos bloques, dirimir procesos de integración —o alianzas hacia uno u otro- polariza a la sociedad, según sus características socioculturales y motivaciones políticas. Este trabajo realiza un análisis sociocultural, económico y político (resultados electorales, predominio lingüístico, minorías étnicas, economía regional) para establecer aproximadas fronteras ocultas en estos espacios, que pueden aflorar en situaciones de crisis, como fue el caso de Ucrania en 2014. En este trabajo se analiza el caso ucraniano para tratar de identificar otras divisorias en Belarús, Letonia y Moldavia, haciendo referencia a las distintas realidades de cada país.

Palabras clave: espacio exsoviético; fronteras; minorías étnicas; separatismo; zona gris europea.

\section{[en] Hidden Borders in the European Gray Zone}

\begin{abstract}
The "European Gray Zone" consists of the spaces of transition between open conflict and peace, currently present on the eastern border of the European Union. This is EU and NATO sphere of expansion, which coincide with the European ex-Soviet space, where Moscow continues to exert a notable influence. In a scenario of growing tension between these two blocks, to resolve integration processes - or alliances towards one or the other- polarizes society, according to its socio-cultural characteristics and political motivations. Through sociocultural, economic and political analysis (electoral results, linguistic predominance, ethnic minorities, regional economy), hidden borders can be established in these spaces, which can emerge in situations of crisis, the case of Ukraine in 2014. This study seeks to analyze the Ukrainian case and tries to identify other divisions in Belarus, Latvia and Moldova, making reference to the different realities of each country.
\end{abstract}

Keywords: ex-Soviet space; borders; ethnic minorities; separatism; European Gray Zone.

\section{[pt] Fronteiras ocultas na zona cinza europeia}

Resumo. A chamada "zona cinzenta europeia" consiste nos espaços de transição entre o conflito aberto e a paz, atualmente presentes na fronteira oriental da União Europeia. É esta a esfera de expan-

1 Departamento de Geografía, Universidad de Murcia (España).

E-mail: miguelborja.bernabe@um.es 
são da UE e da NATO, que coincide com o espaço europeu ex-soviético, no qual Moscovo continua a exercer uma influência notável. Num cenário de tensão crescente entre estes dois blocos, a resolução de processos de integração —ou alianças para um ou outro- polariza a sociedade, segundo as suas características socioculturais e motivações políticas. Este trabalho realiza uma análise sociocultural, econômica e política (resultados eleitorais, dominância linguística, minorias étnicas, economia regional) para estabelecer fronteiras ocultas aproximadas nesses espaços, que podem surgir em situações de crise, como foi o caso da Ucrânia em 2014. Este artigo analisa o caso ucraniano para tentar identificar outras divisões na Belarús, Letônia e Moldávia, fazendo referência às diferentes realidades de cada país.

Palavras-chave: espaço ex-soviético; fronteiras; minorias étnicas; separatismo; zona cinzenta europeia.

Sumario. Introducción. 1. Zona gris y fronteras ocultas. 2. Contexto geopolítico del área de estudio. 3. Metodología. 4. Ucrania: modelo de fragmentación en diversos niveles. 5. Fronteras ocultas en dos escenarios diferentes de la zona gris europea. 5.1. Belarús, un país autoritario. 5.2. Moldavia, un país con un conflicto congelado. 6. ¿Y dentro de la UE y la OTAN? Fronteras ocultas en Letonia. Conclusiones. Agradecimientos. Referencias.

Cómo citar: Bernabé-Crespo, M. B. (2020). Fronteras ocultas en la zona gris europea. Geopolítica(s). Revista de estudios sobre espacio y poder, 11(2), 259-285.

\section{Introducción}

La crisis acontecida en Ucrania entre 2013 y 2014 puso de manifiesto la competencia por el espacio exsoviético y la complejidad de la integración de estos Estados en organizaciones supranacionales como la OTAN, la UE y la EEU (Unión Económica Euroasiática). Desde la desintegración de la URSS y el fin de la Guerra Fría, el llamado "telón de acero" se desvaneció y la esfera occidental amplió sus fronteras hacia el este, incluyendo a los recientes Estados bálticos en ambas Organizaciones, más cerca de Moscú que nunca, e incluso rodeando por completo a parte de su territorio (Kaliningrado) entre Estados aliados de la OTAN. A ello se contrapone la influencia que Rusia ejerce en su vecindario (López, 2018; J. Morales, 2018a). Los restantes Estados exsoviéticos constituyen actualmente una zona de búfer que se encuentra sometida actualmente a una serie de tácticas de influencia geopolítica y que permiten categorizarla como "zona gris". Esta es una contribución a los estudios estratégicos que hace uso de este término elaborado por el US Department of Defense (2010) y caracterizado por otros autores como Baqués (2017) o Jordán (2018) dentro del área de la seguridad internacional.

Las revueltas del Euromaidán pusieron de manifiesto la disyuntiva social y política entre el acercamiento a la Unión Europea o la influencia rusa, y que acabó con la fragmentación de un país de la zona gris: la anexión rusa de Crimea y el conflicto latente en el Donbás. Se estudia tal fragmentación en Ucrania: una división a nivel étnico, lingüístico, económico y electoral, que anticipa la coincidencia de todas estas en un territorio, mostrando el país polarizado y conformando una "frontera oculta" en Ucrania, la cual en un momento de decidir el rumbo de su país, se mostró divergente. El objeto de estudio de este trabajo es analizar la existencia de 
fronteras "ocultas" que alerten sobre una eventual polarización del país, en los casos de Belarús ${ }^{2}$, Moldavia y Letonia.

El término "frontera oculta" se utiliza en este artículo para expresar la coincidencia de fronteras en los niveles estudiados: étnicas, lingüísticas, económicas, electorales. Si todas estas coinciden, nos encontramos ante un país fuertemente dividido internamente en los aspectos básicos de la vida cotidiana, es decir, una parte del país es esencialmente diferente de la otra parte. La hipótesis es que esta "frontera oculta" polariza al país y se puede hacer "visible" en situaciones de tensión sociopolítica, provocadas en gran medida por la acción de actores externos que buscan aumentar su influencia en la zona gris. Son estos lugares de descontento los que pueden catalizar las diferencias y ser el germen de un conflicto, en la línea de la teoría de Rodríguez-Pose (2018). Por lo tanto, su identificación puede servir para la prevención de conflictos en un espacio contestado. En este sentido, debe prestarse especial atención a ciertas regiones estudiadas (Gagauzia y Latgale), donde la realidad difiere notablemente respecto del resto de Moldavia y Letonia. Este artículo se estructura de la siguiente manera: en primer lugar, un encuadre teórico de la "zona gris" y las fronteras ocultas; seguido de un análisis sobre el contexto geopolítico del área de estudio. Después se desarrolla la metodología seguida para el trazado de estas fronteras, y se analiza el modelo ucraniano que prueba esta hipótesis. Por último, se realiza una extrapolación a Belarús —un país autoritario-, a Moldavia - un país con un conflicto congelado-, y también a un país de la UE, Letonia. Por último, se extraen las conclusiones finales.

\section{Zona gris y fronteras ocultas}

El concepto de "zona gris" está marcado por la ambigüedad, al hacer referencia a un terreno situado entre "el blanco" (la paz) y "el negro" (la guerra). Este término fue recogido por vez primera en la Quadrennial Defense Review (QDR) del US Department of Defense: "The future strategic landscape will increasingly feature challenges in the ambiguous gray area that is neither fully war nor fully peace" (2010, p.73). Aceptado y recogido por la comunidad científica, en sus primeras referencias convendría citar a Schadlow (2014) y Kapusta (2015), y posteriormente desarrollado por otros como Hoffman (2016), Wirtz (2017), Jordán (2018) o Englund (2019). Otros autores como Brands (2016) resaltan la complejidad del mismo, y a pesar de su reciente uso, es aplicable a otras regiones donde la confusión y la ambigüedad son intencionadas, para intentar camuflar maniobras hostiles (Jordán, 2018), situación que refleja Morris (2019) para el Mar de China.

Por tanto, "el gris" hace referencia a las situaciones de conflicto político que están entre la paz y la guerra, las cuales, sin constituir una guerra abierta, no se corresponden con las situaciones de paz, al estar esta debilitada por otro tipo de prácticas. Resulta preciso aclarar la diferenciación con respecto al término de guerra híbrida, pues en esta situación ya se encuentra el escenario de guerra convencional implícito (añadido a estrategias de desinformación, injerencias, etc.), mientras que

2 La República de Belarús es el nombre oficial del país y así está reconocido por la Organización de Naciones Unidas, si bien es ampliamente conocido en España como "Bielorrusia". Sin embargo, las autoridades belarusas priorizan este término para reforzar una identidad propia. 
una zona gris se caracteriza por una ausencia de violencia, aun cuando existe un conflicto latente y se persiguen los mismos objetivos. En este sentido, el establecimiento de una zona gris puede constituir una alternativa a la guerra híbrida, una preparación a la guerra híbrida o puede darse en un escenario posconflicto (Baqués, 2017, p.1073). Las estrategias son multidimensionales y se pueden señalar en términos militares (demostraciones de fuerza, vulneraciones del espacio aéreo), políticos (propaganda, respaldo político y financiero), económicos (medidas de coerción económica: sanciones, cortes de suministro energético, negación de créditos), así como el empleo de ciberataques, cuyo objetivo es generar sensación de inseguridad e incompetencia de un gobierno (Baqués, 2017, p.1069). Envueltas en un gradualismo y mediante sliced salami tactics, que impiden percibir de manera nítida el alcance de cada acción, el empleo de todas estas estrategias combinadas tiene como uno de sus mayores éxitos la generación de un descontento social y la movilización de las masas, con lo que se traslada el actor ofensivo hasta el corazón de ese territorio gris. Si, además, se producen infiltraciones canalizadas por distintos medios, asociaciones u organizaciones, recuerda, y están relacionadas con la zona gris, a las proxy wars o guerras por delegación.

El traslado de este concepto al contexto europeo resulta evidente: coincide con el espacio europeo exsoviético, frontera este de la Unión Europea (Mapa 1). Considerado desde la desintegración de la URSS como un espacio de transición o de búfer entre la OTAN y Rusia, está constituido por Estados que han seguido distintos caminos: Estonia, Letonia, Lituania, Belarús, Ucrania y Moldavia (ampliable a las repúblicas caucásicas de Georgia, Armenia y Azerbaiyán si consideramos esta región como europea). Aunque en 1991 se prometió a Gorbachov que la OTAN no ampliaría sus fronteras hacia el Este, las tres primeras repúblicas ingresaron en la UE y OTAN en 2004, en un momento en el que Rusia no tenía capacidad de respuesta y se limitó a aceptarlo, aunque con rechazo (sumado a la propia idiosincrasia de las repúblicas bálticas, que histórica y culturalmente no adquieren la relevancia para Rusia que tiene la histórica Rus de Kiev, el primer Estado eslavo). Belarús, Ucrania y Moldavia encontraron más dificultades en sus relaciones con la UE, debido a su deriva autoritaria en el primer caso (Lukashenko ostenta el poder desde 1994); a sucesivas revoluciones en el segundo caso; e incluso conflictos congelados para el caso moldavo (independencia de facto de Transnistria).

El estudio de las fronteras es objeto de la Geografía, la cual ha teorizado sobre las mismas desde diferentes perspectivas. Así, la escuela alemana identificaba la geografía política con la geografía de los grupos políticos. Ratzel atribuye un papel esencial al suelo, siendo las fronteras y sus movimientos los que marcan la grandeza o decadencia de un Estado. Es este un enfoque determinista, que permitió a Ratzel acuñar en 1901 el término de Lebensraum en su obra "Der Lebensraun, Eine Biogeographische” (López Trigal, 2011) y que posteriormente será asumido por otros pensadores como Winkler o Semple (Ruppert y Schaffer, 1979).

Por su parte, la línea francesa tradicionalmente representó el enfoque posibilista y su máximo exponente, Paul Vidal de la Blache, considera que la frontera no es más que un marco provisional o permanente que no puede estudiarse en sí misma, sino en relación a los grupos que ella separa (Ancel, 2016 [1936], p.132), creando el término "genres de vie". De esta manera se estima que la frontera siempre está determinada por el hombre y nunca por la naturaleza, y en esta misma visión se encuentran discípulos como Sion o Brunhes. Este enfoque posibilista puede ser 
adoptado por la Geografía en el estudio de las "fronteras ocultas" en la zona gris. Son los grupos humanos los que delimitan el territorio según sus géneros de vida, y dado el contexto difuso y ambiguo, pueden exacerbarse cuando se aplican estrategias de desestabilización. En otros casos, estas divisiones internas pueden deberse al abandono político de determinados territorios, y la asunción social de su insignificancia o abandono para el conjunto estatal. Son lugares que no se sienten representados, como refleja Rodríguez-Pose (2018) haciendo una alusión a la "geografía del descontento", que puede generar cuantiosos problemas políticos y territoriales.

Mapa 1. El espacio exsoviético europeo y la zona gris en Europa

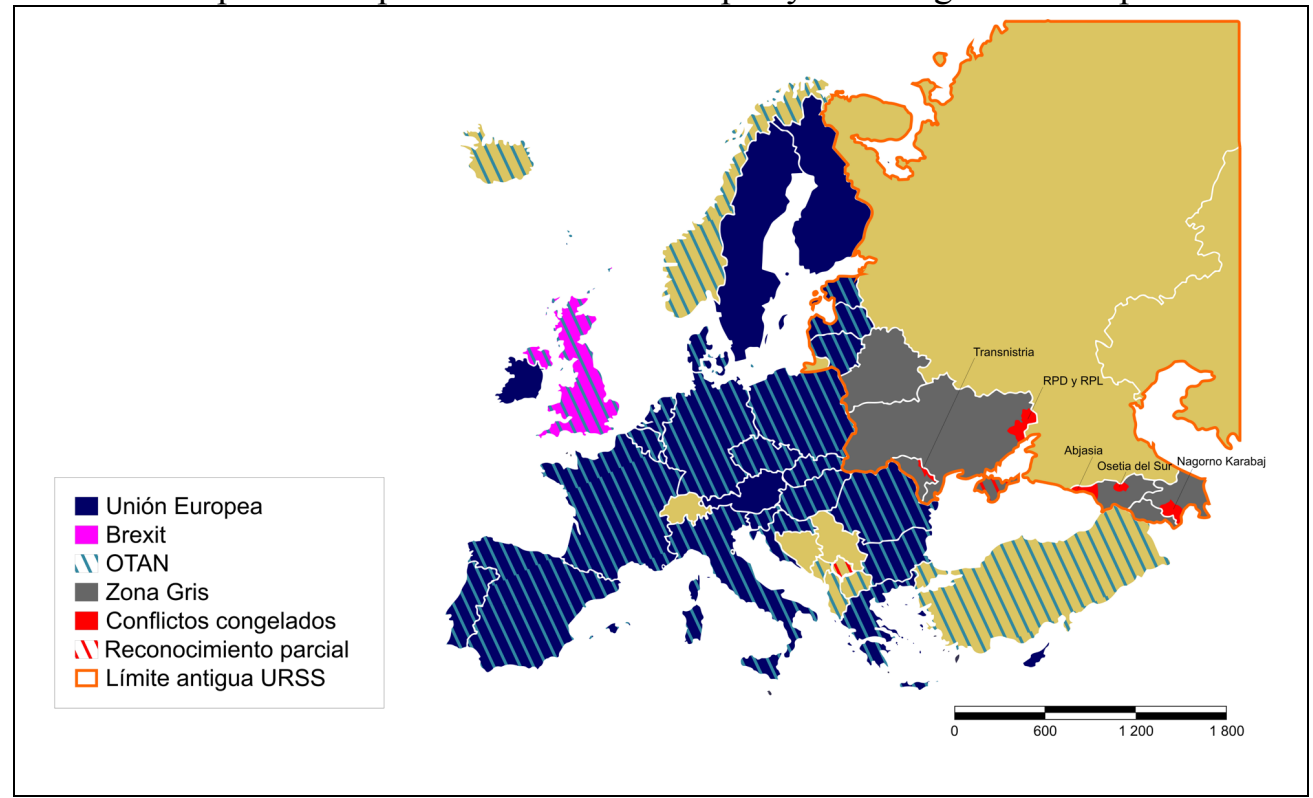

Fuente: elaboración propia.

Las fronteras han sido tradicionalmente líneas que dividían el territorio y lo separaban de "lo otro". Casas et al. (2011, p.87) sostienen que, más que desaparecer o suavizarse, las fronteras están cambiando en forma y contenido, extendiéndose de imprevistas maneras. Las fronteras son difusas en muchos ejemplos: desde fronteras indefinidas en tiempos medievales, fronteras volátiles marcadas por límites naturales cambiantes, ausencia de fronteras en pueblos nómadas y fronteras artificiales... Estos límites divisorios son percibidos según la cercanía sensorial (en el Pacífico el mar une a las islas, en los continentes, las separa) y la seguridad: el fin perseguido es la relación entre los pueblos que tienen voluntades comunes, la seguridad (defensa o protección, frente a pueblos diferentes), que varía con el tiempo (Ancel, 2016 [1936]).

Los cambios de fronteras y trasvases de población han sido frecuentes en la historia europea. Según Hartshorne (1937), las minorías tienden a adaptarse a su entorno, con el paso del tiempo y siempre que ese lapso de tiempo sea lo suficientemente largo y el Estado adopte una adecuada política de integración. Minghi (2018 [1963], p.305) relata que la clave para la asimilación de las minorías suele estar 
siempre en la educación; aunque estas minorías también pueden ser un target de las políticas desestabilizadoras en la zona gris. Motivados por el caso kosovar de 2008 - si bien no son comparables ni equivalentes-, la aplicación del derecho de autodeterminación de los pueblos es el argumento ejercido por Rusia para la defensa del reconocimiento de los Estados de facto de Osetia del Sur y Abjasia (internacionalmente reconocidos como Georgia de iure). Se trata de la Русский мир (Russkiy mir), la retórica de la defensa de las minorías étnicas, que permitió desde ese mismo 2008 a Medvedev apostar por la protección de los ciudadanos étnicamente rusos incluso más allá de sus fronteras, lo que hace a éstas más difusas. Esta proclamación colisiona con el ordenamiento jurídico internacional y el principio de integridad territorial de los Estados (López, 2018, p.55).

Estudiar las fronteras en una zona gris necesita del estudio de los grupos que habitan a ambos lados de ella. En un territorio donde reina la ambigüedad, las fronteras parecen difusas, máxime en un contexto donde las minorías étnicas son grandes en número y fuertemente regionalizadas.

\section{Contexto geopolítico del área de estudio}

Se observa que en esta área europea convergen varios elementos de desestabilización:

- campañas de desinformación; troll factories (como el caso macedonio de Veles, donde se fabricaban noticias falsas favorables a la campaña de Trump en 2016);

- cortes en el suministro de gas, o venta del mismo a Lituania a precios mayores que a Alemania o importantísimas rebajas a Belarús;

- ciberataques (como el de Estonia en 2007 o Georgia en 2020);

- respaldo político hacia partidos afines (incluyendo el que Moscú otorga a los partidos de ultraderecha europeos, los cuales cuestionan la pervivencia de la UE).

Estas estrategias cobran fuerza cuando el actor que desestabiliza la zona gris está menos institucionalizado (Rusia) que las democracias perjudicadas (Baqués, 2017, p.1054). Por lo tanto, parecen cumplirse los elementos para categorizarla como "zona gris", aunque esto suponga cuestionar la paz formalmente existente.

Samuel Morales (2015, p.89) señala que a Rusia le queda poco poder blando con el que maniobrar (entendido este como la influencia mediante una cultura atractiva, valores políticos y política exterior con autoridad moral), por lo que se inclina más hacia un comportamiento ofensivo. Sus acciones de propaganda y fomento del nacionalismo aprovechan los sentimientos de la Gran Guerra Patria (II Guerra Mundial), en una lucha denominada antifascista que, ante amenazas reales o imaginarias, sirve de factor de unión. Estas acciones no constituyen una nueva "guerra fría", en un orden mundial multipolar y con una distribución del poder más fragmentado y difuso. Moscú está muy alejado de aquel contexto (J. Morales, 2018a, p.144), pero sí se identifica con una potencia que trata de frenar el avance de otra superpotencia por medio de guerras híbridas y el establecimiento de una zona gris. Rusia parece desarrollar un expansionismo defensivo, motivado por la 
sensación de inferioridad e inseguridad (Jovaní, 2014). Esta sensación de amenaza exterior constante es una herramienta de unión y de apoyo al liderazgo: Rusia no reacciona ante un peligro físico (J. Morales, 2018b, p.10), sino que defiende su identidad como superpotencia (derzhavnost), lo cual implica mantener la influencia en el espacio exsoviético, y ejercer presión al denominado vecindario en disputa, como relata Lanoszka (2016).

La competición por este espacio es patente, por ejemplo, con las declaraciones en la XX Cumbre de la OTAN en Bucarest, en abril de 2008, donde se expresó la futura incorporación (aunque sin fecha) de Ucrania y Georgia en la OTAN; y también con la acuñación del término blizhneyezarubezhye, la política exterior en relación a los países vecinos. El suceso más destacado tuvo lugar en noviembre de 2013 con la firma del Acuerdo de Asociación entre la UE y Ucrania. El entonces presidente Yanukóvich, prorruso y afín al Kremlin, decidió a última hora no firmar tal acuerdo, lo que originó las protestas en la Plaza de la Independencia (Maidan Nezalezhnosti, conocidas como las revueltas de Maidán o Euromaidán) en Kiev. Las ofertas de integración en la Unión Europea (UE) y en la Unión Económica Euroasiática (EEU, unión aduanera promovida por Rusia) son exclusivas. Como señalan Ademmer, Delcour y Wolczuk (2016), la membresía en la EEU supone una pérdida de soberanía sobre el comercio exterior y no es compatible con el establecimiento de otras áreas de libre comercio, que pudieran ser europeas. El derrocamiento de Yanukovich y la formación de un nuevo gobierno (en el que la ultraderecha jugó un destacado papel) alentaron la retórica rusa del antifascismo, la defensa de las minorías rusas y la consiguiente anexión en 2014 de Crimea -un hecho consumado, aunque no reconocido- y la proclamación de las autodenominadas Repúblicas Populares de Lugansk (RPL) y Donetsk (RPD). El conflicto, todavía no resuelto, ha ocasionado un empeoramiento de las relaciones entre Occidente y Rusia, sanciones económicas, amén de numerosas víctimas. E implica un aumento de la tensión en esta zona gris, que trata este trabajo.

\section{Metodología}

Para la realización de este trabajo se ha consultado bibliografía especializada, y entre las fuentes se incluyen los datos de la Oficina Central de Estadística de Letonia, la Comisión Central de Elecciones de Letonia, la Comisión Central Electoral de Moldavia, la Oficina Nacional de Estadística de Moldavia, el Comité Estatal de Estadísticas de Ucrania, del Ministerio de Finanzas de Ucrania, la Comisión Central Electoral de Ucrania y el Comité Nacional de Estadística de la República de Belarús, así como la visita a estos países para observar sobre el terreno estas diferencias internas.

Se ha tomado el estudio del caso ucraniano como modelo extrapolable a otros países de la zona gris. El presente trabajo realiza, en primer lugar, un análisis de la división interna en Ucrania. Huntington (1996) ya anticipó que Ucrania era un país que se debatía entre la esfera occidental y la rusa e incluso lo calificó como "Estado fracturado". La crisis iniciada en 2013 motivó la fragmentación del país y evidenció las fronteras ocultas, que culminaron en referendos no reconocidos y la posterior anexión de Crimea a Rusia y la proclamación de la RPL y RPD. 
La justificación de la elección del modelo ucraniano reside en que se trata del primer caso de fracturación interna de un país en un contexto de zona gris (el conflicto congelado de Transnistria fue una guerra convencional; la invasión de Georgia en 2008 se produjo sobre repúblicas autónomas). El esquema de trabajo propio para abordar esta problemática estudia las diferencias territoriales en los niveles de:

1) Etnicidad: proporción de minorías, ya que la procedencia de un Estado madre puede ser usado como retórica para una injerencia, o la misma distribución de pasaportes (pasportización) y defensa de nacionales. Además, como sostienen Ezcurra y Rodríguez-Pose (2017), la segregación étnica está asociada con altos niveles de desigualdad.

2) Lengua: uso del idioma y políticas lingüísticas adoptadas.

3) Economía: salario percibido y ocupación, ya que las políticas pueden favorecer o perjudicar a diferentes sectores. Además, se pone énfasis entre la distinción de rural y urbano, ya que una guerra híbrida es esencialmente urbana (Baqués, 2015, p.46).

4) Política: análisis de los resultados electorales.

A partir de esta idea, se propone identificar fronteras ocultas en otros países de la zona gris europea. Los mapas elaborados reflejan las fronteras internas en los niveles mencionados. Las líneas trazadas responden a estas diferencias, que siguen los límites administrativos internos, aunque con un estilo suavizado para mejorar su legibilidad y simplificación, cuyos datos han sido extraídos de las fuentes citadas.

Se han tomado tres casos de estudio referidos a tres países con situaciones políticas diferentes. La elección de ellos trata de recoger tres situaciones dispares pero que potencialmente pueden entrar en conflicto debido a sus características internas. En consecuencia, se ha escogido Belarús, un país autoritario y que geográficamente constituye el único espacio de la zona gris encajado entre Rusia y la UE - obviando Ucrania donde ya se ha producido un conflicto-; Moldavia, un país con estrechos lazos con Rumanía (UE) pero que resiste un conflicto congelado (Transnistria); y Letonia, un país ya integrado en la UE y OTAN, el Estado báltico con mayor proporción de ciudadanos rusos, densamente localizados en su región sureste.

\section{Ucrania: modelo de fragmentación en diversos niveles}

Ucrania es un Estado clave para la geopolítica europea y mundial. Su importancia estratégica se constata en su emplazamiento entre Europa y las puertas de Asia: Ucrania es el corredor de los suministros energéticos para Europa central y el acceso al Mar Negro para Rusia. El factor cultural de Ucrania para Rusia ocupa un lugar destacado, pues la Rus de Kiev fue el primer Estado eslavo, establecido en el siglo IX (que posteriormente trasladaría su centro de gravedad a las inmediaciones de Moscú). Ucrania, además, era considerada "el granero de la URSS"; lugar de ciudades cosmopolitas y con proyección europea como Odesa, fundada por Catalina la Grande en el siglo XVIII; Dniepropetrovsk (actual Dnipro, nomenclatura ucraniana), era un lugar de establecimiento de las más importantes fábricas de armas nucleares; lugares de importante industria del turismo, como Yalta, donde 
además se escenificó la victoria sobre el nazismo. En definitiva, fue considerada el pueblo hermano de los rusos: gesto de ese hermanamiento fue la cesión de Crimea de la RSFS de Rusia a la RSS de Ucrania en 1954, para conmemorar el 300 aniversario del Tratado de Pereyaslav, en el que Ucrania aceptó la protección del Imperio ruso.

La desintegración de la URSS fue firmada por los presidentes de las repúblicas de Rusia, Belarús y Ucrania en diciembre de 1991. Desde entonces, Ucrania ha orbitado entre la influencia rusa y la occidental. Mediante el Memorando de Budapest de 5 de diciembre de 1994, sobre Garantías de Seguridad, Ucrania cedió a Rusia 5.000 bombas nucleares, 220 vehículos de largo alcance, 176 misiles balísticos y 44 aviones bombarderos con capacidad nuclear. Rusia, por su parte, aceptaba la integridad territorial de Ucrania y la inviolabilidad de su soberanía (Byllk, 2018, p.171). Tres años más tarde, se ratificaban las buenas relaciones ruso-ucranianas, al respetar mutuamente la integridad territorial y reafirmar la inviolabilidad de las fronteras actualmente existentes, tal y como se especificaba en el Tratado de Amistad, Cooperación y Asociación entre Ucrania y la Federación Rusa del 31 de mayo de 1997. Aunque las relaciones han sido dañadas en ocasiones (por ejemplo, debido a los cortes de suministro de gas a Ucrania, o por la llamada "Revolución naranja" de 2004), fueron los sucesos del Euromaidán los que marcaron un antes y un después. Rusia, que había visto cómo tres repúblicas exsoviéticas (Estonia, Letonia y Lituania) ya se integraron en la comunidad europea y en la alianza noratlántica, no podía perder el control del último bastión, que había jugado tradicionalmente un papel de tapón. Ante la inminente firma del Acuerdo de Asociación en 2013 con la Unión Europea, las presiones de Moscú hicieron que el entonces presidente Víktor Yanukóvich rehusara firmarlo, lo que desencadenó una ola de protestas y manifestaciones en el país. La presencia de la ultraderecha ucraniana fue clave para dinamitar las protestas pacíficas y radicalizar aún más el país.

La ocupación de edificios públicos, mayoritariamente en el oeste y centro de Ucrania, y el cambio de gobierno motivaron que en las regiones del este y sur de Ucrania surgiera una contrarrevolución, con marcado discurso antifascista, en la que se declararon varias repúblicas independientes (como la de Járkov, aunque fuera de corta duración) con la intención de constituir una confederación conocida como Novorossiya (Nueva Rusia), el nombre con el que se conoció a estos territorios de nuevos pobladores eslavos tras la conquista contra los turcos en el siglo XVIII. De esta confederación, actualmente solo resisten las autodenominadas Repúblicas Populares de Donetsk y Lugansk.

El llamamiento de las autoridades crimeas a Rusia para su protección se constató en la presencia repentina de "hombrecillos de verde", militares no identificados, que ocuparon la península. Tras la declaración de independencia de la República de Crimea, esta solicitó adherirse a la Federación Rusa, lo que fue aprobado por referéndum por Crimea y ratificado por Rusia días después. Este proceso fue calificado por la mayoría de la comunidad internacional como una ruptura de las reglas de juego, lo que ha motivado su no reconocimiento (Allison, 2014).

En síntesis, en esta situación de crisis se evidenció una dualidad de aparente división de Ucrania (Mapa 2): el oeste y centro del país apoyó mayoritariamente el Euromaidán; mientras que en el sur y este se produjeron las protestas con más tensión, masacres e incluso guerra civil. 
Mapa 2. División de Ucrania según el apoyo al Euromaidán y a las protestas prorrusas en $2014^{*}$

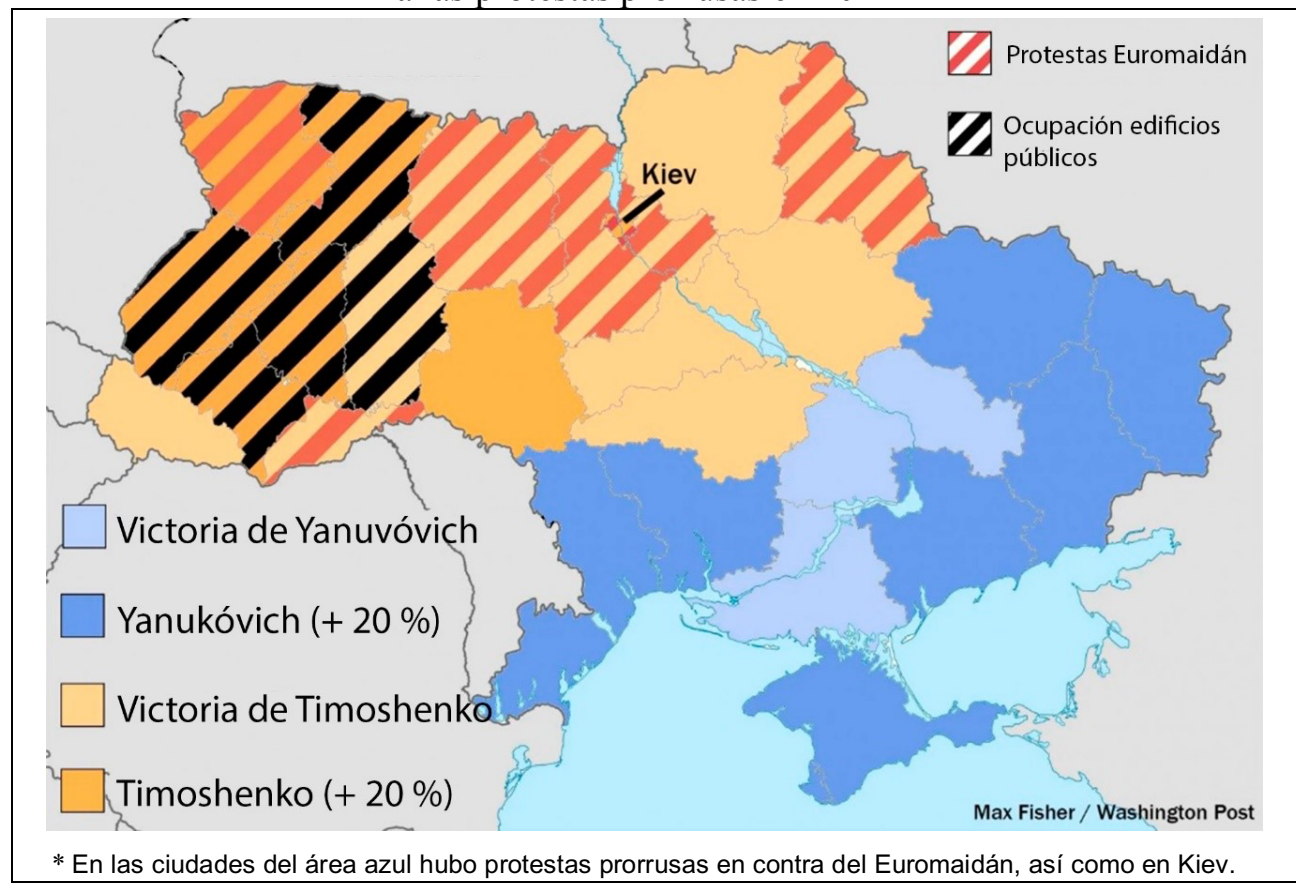

Fuente: The Washington Post (2014).

A continuación, se procede a un análisis de tal división siguiendo el esquema de trabajo planteado en cuatro niveles (Mapa 3):

1) Etnicidad: en el centro y oeste del país los ucranianos representan más del $90 \%$ del total de la población, donde el óblast ${ }^{3}$ de Ternopil alcanza el 97,8\% de ucranianos. En esta zona, la proporción de rusos es, por lo general, inferior al $7 \%$, siendo un 1,2 \% en Ternopil. Por el contrario, en el sur y este de Ucrania, los porcentajes de ucranianos son los más bajos: $24,3 \%$ en Crimea y 56,9 \% en Donetsk. Es en estas regiones donde los rusos cuentan con mayores proporciones: $39 \%$ en Lugansk, y son mayoría en Crimea (58,3\%). Otras minorías importantes son los húngaros en Zakarpatska, o rumanos en Chernivtsi (Deržavna služba statistiki ukraïni, 2001).

2) Lengua: el ucraniano es utilizado como idioma de comunicación habitual en el oeste y centro de Ucrania (97\% en Volinia y Rivne); mientras que el ruso es el $74,9 \%$ en Donetsk o el $77 \%$ en Crimea (Deržavna služba statistiki ukraïni, 2001). En este aspecto, es necesario incidir que la Ley sobre las bases de la política lingüística estatal de 2012 (promulgada por Yanukóvich) establecía que en los raiones donde un determinado idioma fuese hablado por al menos $10 \%$ de los

Óblast es una división administrativa subnacional, semejable a región o provincia. Un óblast se subdivide en raiones. Un raión o rayón es una subdivisión administrativa comparable a un distrito en zonas urbanas y a comarca en zonas rurales. 
habitantes, dicho idioma podía adquirir el rango de lengua cooficial. Esta ley fue abolida por el nuevo gobierno tras el Euromaidán.

Mapa 3. Diferencias étnicas, lingüísticas y económicas en Ucrania

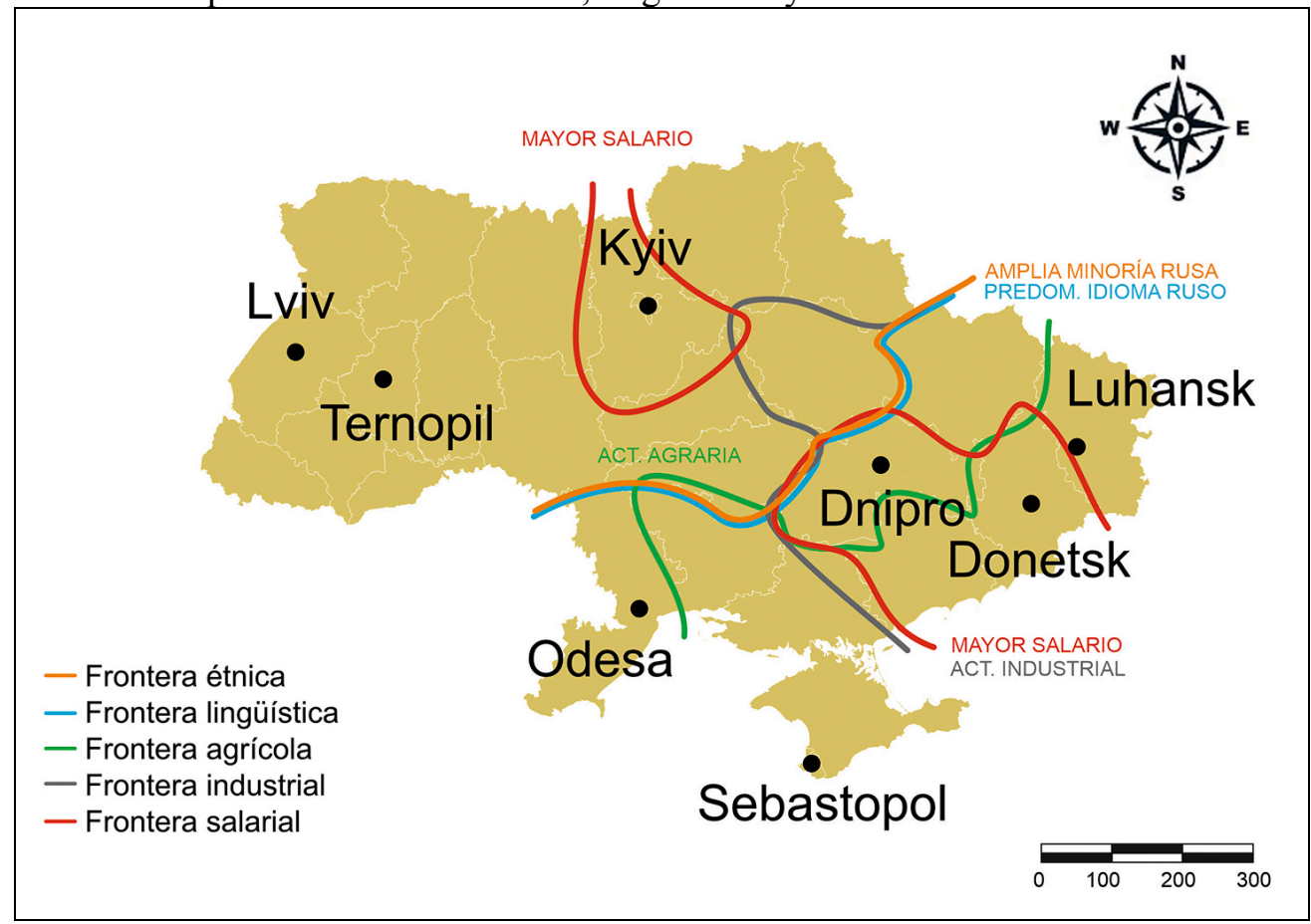

Fuente: elaboración propia.

3) Economía: el centro de Ucrania es un territorio eminentemente agrario, donde los suelos chernozem posibilitan una agricultura de grandes rendimientos, sobre todo de remolacha, cereales, patatas y girasoles (óblasts de Vinnytsia, Poltava, etc.). En el este, es la minería la actividad principal, lugar de la cuenca minera del Donbás, de gran tradición histórica, que también propició el establecimiento de una importante industria como la metalúrgica (óblasts de Dniepropetrovsk, Donetsk, etc.). El salario percibido también es desigual: exceptuando la capital Kiev, los más altos se encuentran en Donetsk (cerca de 6.000 grivnas), Zaporizhia y Dniepropetrovsk (más de 5.000). Por el contrario, Ternopil y Chernivtsi, en el oeste, están por debajo de 3.800 grivnas (Mìnfin, 2016).

4) Política: Por último, el análisis electoral refleja una situación de marcadas divisiones respecto de los óblast que componen Ucrania, prolongadas y constantes, con pequeñas variaciones, entre las que se destacan los casos más llamativos (Mapa 4). En el referéndum de independencia de 1991, si bien en la totalidad de Ucrania el resultado fue a favor, las diferencias son significativas: $98 \%$ en Ivano Frankivsk y Ternopil, $97 \%$ en Lviv, frente al $83 \%$ de Lugansk y Donetsk. Únicamente el $54 \%$ de la población de Crimea votó a favor de la independencia ucraniana respecto de la URSS, razón por la cual se constituyó la República Autónoma de Crimea dentro 
de la Ucrania independiente. Las elecciones presidenciales de 1994 ya evidenciaron la dicotomía electoral: mientras que en el oeste ganaba Kravchuk (el expresidente de la RSS de Ucrania, que firmó la disolución de la URSS) con más del $90 \%$ del voto en Ivano Frankivsk, Chernivtsi o Lviv, en el este y sur de Ucrania el ganador era Kuchma, con más del $85 \%$ en Crimea y Lugansk. Yanukovich (líder del Partido de las Regiones, prorruso) y Yushchenko (nacionalista) se medían en las elecciones de 2004, las más controvertidas (Kuzio, 2005). En la campaña, Yushchenko acusó de haber sido envenenado y, después de una derrota en las urnas ante Yanukovich, en unas elecciones fraudulentas, la sociedad comenzó la llamada "Revolución Naranja", del color del partido de Yushchenko. Después de la repetición de las elecciones, este último fue proclamado ganador consiguiendo más del $90 \%$ de los apoyos en Volinia, Lviv, Ivano Frankivsk y Ternopil, en el oeste; mientras que Yanukovich sumó más del mismo porcentaje en Donetsk y Lugansk.

Mapa 4. Resultados electorales en Ucrania en 1994, 2004, 2010 y 2012

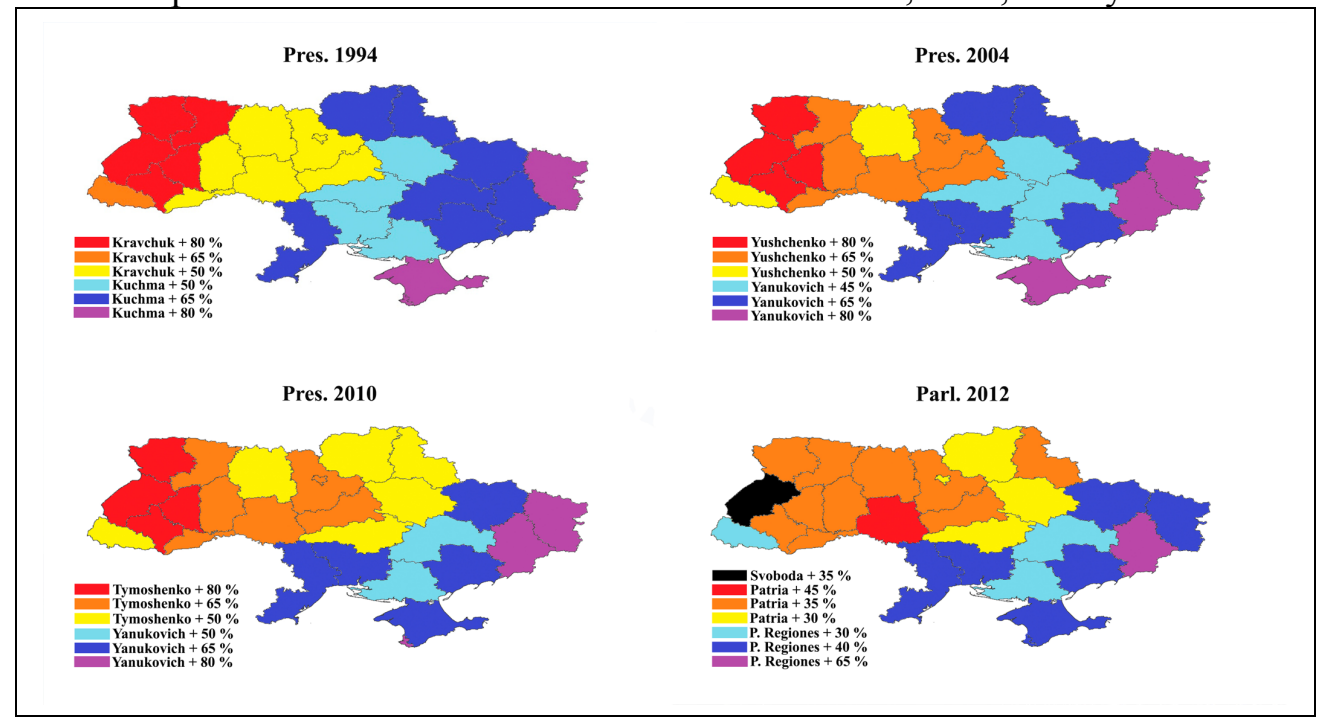

Fuente: Tsentralnoy Viborchoi Komisiy (Центральної виборчої комісії).

Seis años más tarde, en 2010, el mismo Yanukovich se volvía a medir en las elecciones ante Timoshenko, del partido Patria, nacionalista y proeuropeo. Timoshenko reunió más del $80 \%$ en las regiones del oeste, mientras que Yanukovich revalidaba sus anteriores exitosos resultados en las zonas del este y sur de Ucrania, consiguiendo esta vez la presidencia de Ucrania. Meses después, Timoshenko fue encarcelada alegando irregularidades en contratos de gas, aunque fue vista por la comunidad occidental como una prisionera política. Las elecciones parlamentarias de 2012, las últimas antes del Euromaidán, ya vieron surgir al partido de extrema derecha Svoboda, venciendo el raiones como Lviv.

Atendiendo a estos análisis se constata la frontera oculta en Ucrania: un centro y oeste del país de mayoritaria presencia étnica ucraniana, donde el ucraniano es el idioma utilizado, de fuerte dependencia agraria, con salarios más reducidos e inclinado políticamente hacia el nacionalismo y el proeuropeísmo; frente a un sur y este 
de Ucrania con una importante minoría de rusos, donde el ruso es el idioma más hablado, de larga tradición industrial, con salarios más altos que el resto del país, y volcado electoralmente hacia los partidos prorrusos, descentralizadores y euroescépticos. Estas diaclasas apenas imperceptibles se convierten en fallas ante situaciones de crisis como ocurrió en 2014, y coinciden con los territorios que experimentaron un menor o mayor apoyo, movilizaciones y revueltas que han conducido al enfrentamiento civil. Exceptuando el caso de Crimea, de enorme importancia estratégica para Rusia (en Sebastopol se encuentra la flota del Mar Negro), la postura de Moscú no parece ser anexionar los territorios prorrusos del Donbás (de hecho, no reconoce formalmente a la RPD y RPL), sino propiciar la aparición de conflictos congelados, una forma de desestabilizar el país y ostentar cierto control. Estos hechos han elevado el apoyo de la sociedad ucraniana a la integración en la OTAN, cuando hasta entonces era algo minoritario comparado con el deseo de formar parte de la UE (Claudín, 2015, p.93), algo que Rusia trata de impedir (uno de los requisitos es la integridad territorial y control fronterizo).

\section{Fronteras ocultas en dos escenarios diferentes de la zona gris europea}

\subsection{Belarús, un país autoritario}

Belarús ha transitado históricamente entre el dominio polaco-lituano y el ruso, con un breve periodo de independencia entre 1918 y 1919, tras la I Guerra Mundial. Considerado uno de los socios más fieles del Kremlin, desde 1994 se encuentra dirigida por Alexandr Lukashenko, que ha establecido un régimen autoritario, tildado por la comunidad occidental como "la última dictadura de Europa". De hecho, es el único país no miembro del Consejo de Europa, ya que no es considerada una democracia. A pesar de los tratados de unión entre Rusia y Belarús, de la predisposición y apoyo belaruso a la EEU e incluso algunas declaraciones de unión política entre ambos Estados, las relaciones no siempre han sido excelentes. El apoyo de Belarús al gobierno surgido de la "Revolución Naranja" de Yushchenko, a Saakashvili en la Georgia post-2008 (tras la guerra de Osetia del Sur), el no reconocimiento de Abjasia, Osetia del Sur, ni la anexión de Crimea son pruebas de ello (Claudín, 2015). A ello se suman las últimas tensiones, como las discrepancias en torno a la instalación de una base aérea en Belarús, la influencia de los medios de comunicación rusos, el obstáculo a la recuperación de los símbolos identitarios y la construcción de la cooperación con EE UU y la UE, lo que coloca a Belarús como un foco de inestabilidad susceptible de protagonizar algún tipo de intervención reactiva (López, 2018, p.62).

Tras los eventos de Ucrania en 2014, el régimen de Lukashenko ha sufrido un lavado de cara frente a la Unión Europea (la cual levantó las sanciones en 2015), ya que se ofreció como mediador entre las partes y Minsk fue la ciudad donde se firmaron los acuerdos encaminados a la paz en el Donbás. Aunque Belarús sigue siendo un firme apoyo de Rusia, y su acercamiento a la UE sigue siendo muy tímido (si bien en 2017 flexibilizó el turismo mediante la exención de visado), el estudio llevado a cabo por Korosteleva (2016) muestra una opinión pública reevaluadora de prioridades conectadas con la identidad propia y de futuro. Entre las principales conclusiones extraídas, se resalta que dos tercios de los encuestados 
creen que se necesita un marco de cooperación más fuerte con la UE, y la mayoría de los que respondieron ( $54 \%$ ) perciben la relación con la UE como muy positiva, un $12 \%$ más que en 2009 . De igual manera, también se ha elevado la proporción de los que desconfían (16\%, que supone un aumento del $7 \%$ desde 2013), lo que posiblemente esté relacionado con los eventos en Ucrania y las relaciones problemáticas de la UE con Rusia. En resumen, se señala el aumento del dilema de cooperación de Belarús, que en vista de las solapadas competencias entre la UE y la EEU, puede potencialmente ser divisivo y desestabilizador para el status quo del país. Es por ello que resulta de enorme interés el tratar de identificar ciertas fronteras internas (Mapa 5) que puedan salir a la luz en un escenario de crisis (datos extraídos del Comité Nacional de Estadística de la República de Belarús, Nacional'nыj statističeskij komitet Respubliki Belarus', 2019).

Mapa 5. Diferencias étnicas, lingüísticas y económicas en Belarús

- Frontera étnica

- Frontera lingüística

- Frontera agrícola

- Frontera salarial

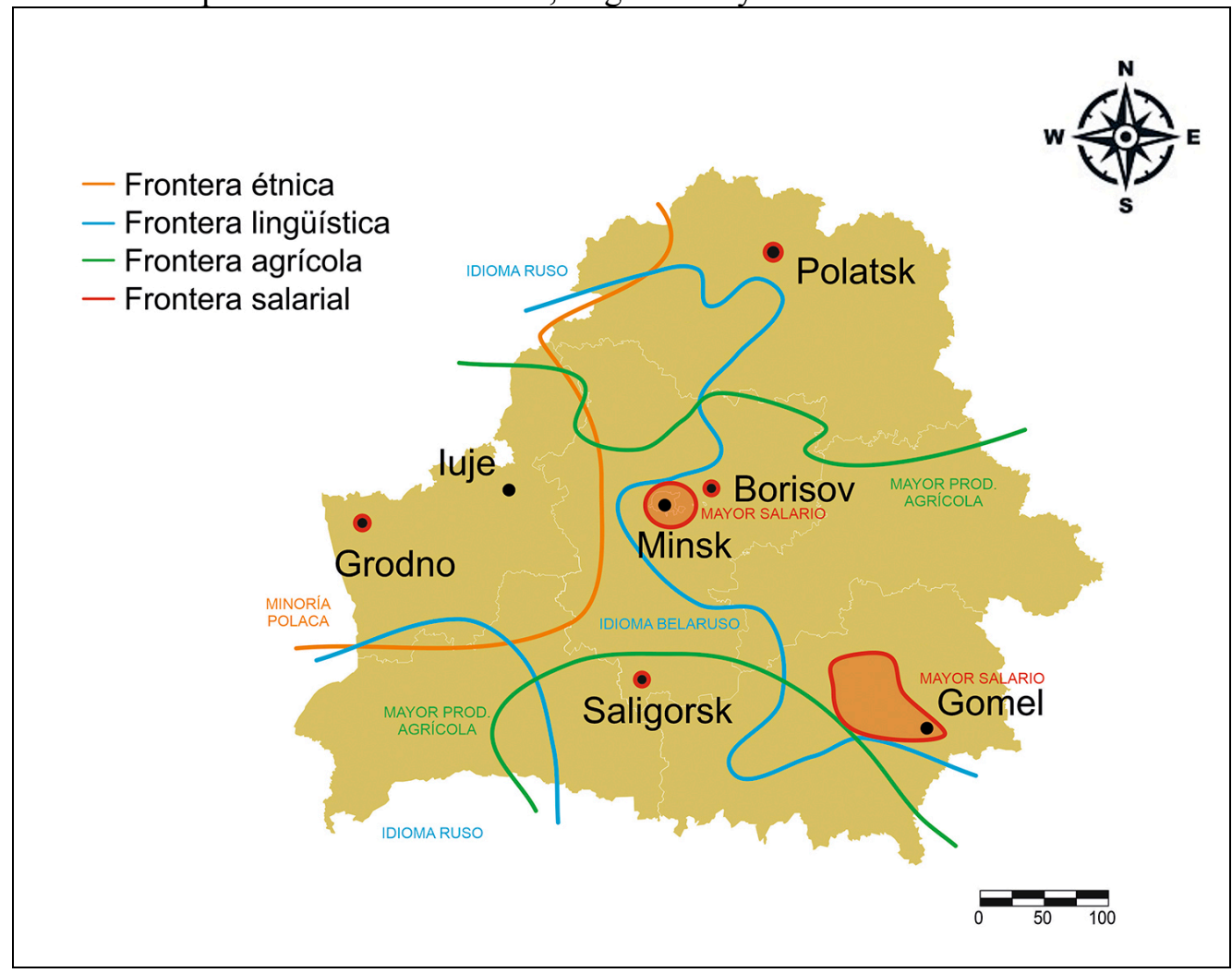

Fuente: elaboración propia.

1) Étnicamente, se resalta la difícil distinción entre ruso y belaruso, ya que este último término no ha tenido un recorrido histórico independiente. La minoría más importante es la polaca que, además, registra un asentamiento más localizado: en las regiones del oeste próximas a Lituania, como en los raiones de Grodno, Lida, Shchuchyn o en Voronovo, donde llegan a suponer más del $80 \%$. 
2) Lingüísticamente, el idioma ruso predomina en las ciudades, mientras que el belaruso queda relegado a un ámbito rural. Los raiones en los que el belaruso es utilizado por mayor proporción de población se sitúan en el oeste y sur del país, siendo los de Sharkaushchyna, Iuje, Valozyn, Kletsk y Kapyl los que logran porcentajes superiores al $80 \%$. Por el contrario, en todas las grandes ciudades y en los raiones de Brest, Kamyanyets, Zabinka, Borisov y Vitebsk el $80 \%$ usa el ruso como idioma habitual.

3) Económicamente, los raiones que disfrutan de salarios más altos son la capital, Minsk, y los de Recyca, Zhlobin, Mozyr y Gomel en el sureste del país; además de Saligorsk, en el centro-sur. El resto del país consigue unos salarios bajos, extendidos uniformemente y solo paliados en ámbitos urbanos. En cuanto a la ocupación, las mayores producciones agrarias se sitúan en el centro, oeste, suroeste y sureste del país, siendo la de Grodno la más productiva. La industria del país es escasa y su producción más notable es la de maquinaria agraria, como tractores o camiones.

\section{Mapa 6. Resultados electorales en Belarús, 1994}

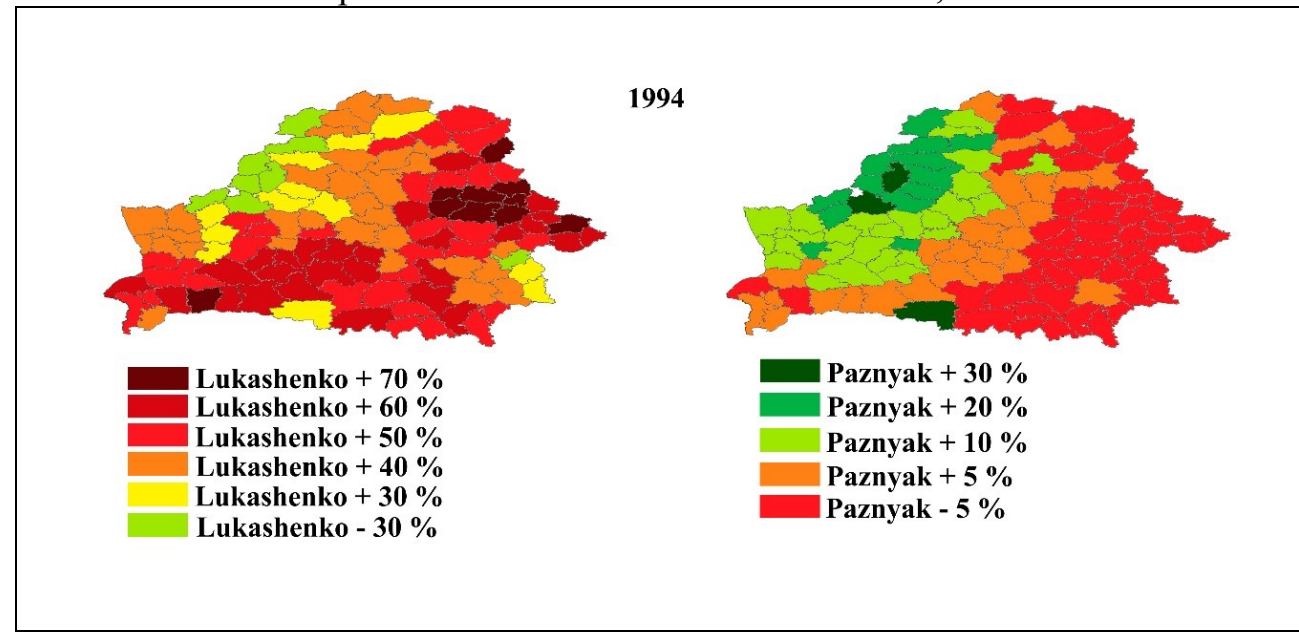

Fuente: Sahm (2010).

4) Electoralmente solo se puede contar con los datos de las elecciones de 1994 (Mapa 6), consideradas como las últimas libres (en las sucesivas, Lukashenko ha llegado a ganar con más del $80 \%$ de los votos y con una prácticamente nula oposición). En estas elecciones, Lukashenko ganó por amplia mayoría (80 \%), concentrando su voto mayoritario en las regiones del este y sur de Belarús. En estas elecciones destaca el voto al Frente Popular Belaruso, partido nacionalista belaruso y proeuropeo (cuyo líder Paznyak huyó a Estados Unidos en 1996), con un voto concentrado en la faja oeste del país, que de norte a sur coincide con los territorios históricos asociados a la República de las Dos Naciones. En raiones como Iuje, Smarhon o Stolin logró más de $30 \%$; y en Minsk superó el $20 \%$, por encima de Lukashenko (algo menos del $20 \%$ ) (Nohlen y Stöver, 2010). Mientras que en el este (tanto norte como sur) apenas consiguió votos (por lo general, menos del $5 \%$ en cada raion). Por otra parte, Dubko, el candidato del Partido Agrario, consiguió 
sus mejores resultados en los raiones donde la producción agraria es mayor, como Grodno.

Tras este análisis, se constata que en Belarús no existe una división tan dicotómica como en Ucrania, si bien se aprecian ciertas diferenciaciones. El oeste del país, que coincide con la extensión del área de influencia histórica polaco-lituana, aglutina a una importante minoría de polacos, coincide también con áreas eminentemente rurales y donde el belaruso es el idioma más hablado. Estas regiones mostraron un apoyo más comedido a Lukashenko en 1994, y optaron por Paznyak, el candidato opuesto ideológicamente.

\subsection{Moldavia, un país con un conflicto congelado}

La actual República de Moldavia se sitúa geográficamente en el territorio de la histórica Besarabia, el umbral entre la influencia rusa y otomana. Su estrecha relación con Rumanía no es casual: el principado de Moldavia (que actualmente corresponde al territorio de la Moldavia rumana, con capital en Iasi) fue el germen del Estado rumano, con la figura del moldavo Alexandru Ioan Cuza, que aglutinó a Valaquia y Moldavia. El Reino de Rumanía incluyó a Moldavia hasta la II Guerra Mundial, cuando la URSS anexionó la parte oriental creando la RSS de Moldavia, añadiendo la franja de la margen izquierda del Dniéster (Transnistria). Con la desintegración de la URSS, las RSS acceden a su independencia, pero en el caso moldavo la integridad no estaba asegurada. Los gagauzos, pueblo turco de confesión ortodoxa, declararon su independencia de Moldavia en 1991. Posteriormente lograron un acuerdo con el gobierno moldavo para constituirse como entidad territorial autónoma y lograr derechos para esta minoría. Por su parte, Transnistria, por temor a una rumanización (debido a la existencia del movimiento unificador con Rumanía), libró una guerra civil en 1992 que concluyó con la independencia de facto transnistria, aunque no ha sido reconocida por ningún país. La nostalgia soviética en Transnistria es evidente, donde la hoz y el martillo ondean en su bandera. Protegida por el XIV Ejército soviético, Transnistria es un conflicto congelado que subsiste gracias al apoyo ruso. En un periodo de inquietud geopolítica en la frontera este de la Unión Europea, Transnistria es un punto caliente: las especulaciones incluyen la formación de un corredor Rusia - Novorossiya - Transnistria, al mismo tiempo que desde Rumanía se lanzan mensajes de unificación con Moldavia. En 2006, Tiraspol ya organizó un referéndum en el que el 97,2\% de la población deseaba unirse a Rusia. Por la parte gagauza, en su capital Komrat se organizó un referéndum en febrero de 2015 , con una participación del $70 \%$, en el que el $98,4 \%$ de los votantes apoyó estrechar relaciones con la EEU, mientras que simultáneamente, el 97,2 \% se oponía a la integración en la UE (Beyer y Wolff, 2016, p.346). El esquema de trabajo, según datos de Statistica Moldovei (2019), arroja los siguientes hallazgos (Mapa 7):

1) El análisis étnico encuentra, en primer lugar, una pregunta que resolver: la diferenciación entre "moldavo" y "rumano". A menudo son considerados equivalentes, aunque el nacionalismo moldavo establece ciertas diferencias entre ellos. La distribución de moldavos (o rumanos) ocurre a lo largo de todo el país, con mayores proporciones en el centro y sur. Los moldavos representan más del $98 \%$ en Tele- 
nesti, Dubasari o Nisporeni; mientras que en Gagauzia son solo el 4,7 \%, o en Taraclia el 14,2 \%, en el sur; o el $63 \%$ en Ocnita y Balti, en el norte. Los rusos y ucranianos obtienen en estos últimos municipios sus proporciones más elevadas: $34,5 \%$ en Balti y 29,6 \% en Ocnita. Los gagauzos son el $84 \%$ en su territorio autónomo (y apenas se encuentran fuera de él: por lo general, representan un $0,1 \%$ en otros distritos). Por último, los búlgaros son mayoría en Taraclia (66 \%) y bajamente repartidos en otros distritos.

Mapa 7. Divisiones étnicas, lingüísticas y económicas en Moldavia

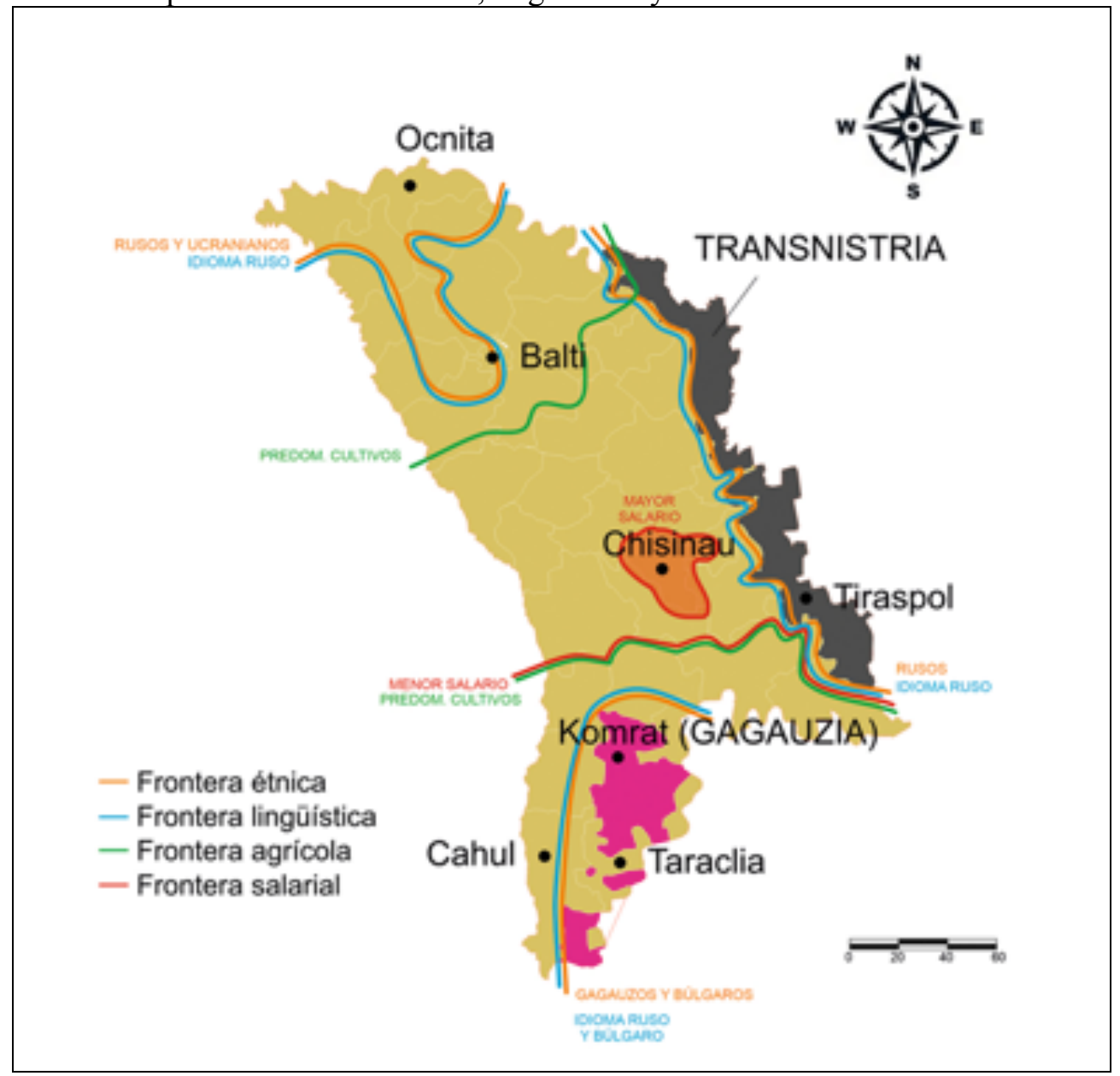

Fuente: elaboración propia.

2) En clave idiomática, la frecuencia de hablantes se corresponde con el anterior análisis a nivel étnico. Los rumanoparlantes son mayoría en todos los distritos salvo en Taraclia (el rumano es utilizado por el $8,8 \%$ de la población, mientras que el búlgaro llega al $50 \%$ y el ruso al $40 \%$ ); en Gagauzia (el $1 \%$, siendo el gagauzo el empleado por el $56 \%$ de la población y el ruso por el $41 \%$ ); y en Balti solo llega al $48 \%$, donde el idioma ruso es hablado por el $51 \%$ de la población. 
3) Atendiendo a la superficie dedicada a cultivos, el norte cuenta con más de 389.000 ha; el sur con 265.000 y el centro con 189.000. La entidad territorial de Gagauzia reúne más de 85.000 ha de cultivo. Después de ella, los municipios con mayor superficie de cultivo son Drochia y Floresti en el norte, y Cahul en tercera posición en el sur. En cuanto a la industria, Chisinau produce el 54, $3 \%$ del valor industrial del país, seguida muy por detrás por Balti con el $11 \%$. Los valores industriales más bajos se encuentran en el sur, que en el conjunto de toda la región solo produce el 3,7 \%; y en Gagauzia es del 3,6 \%. En cuanto a los salarios percibidos, la capital Chisinau suma los valores más altos con más de 3000 lei mensuales por persona; mientras que la región del sur solo alcanza los 1984. Los ingresos por actividad agrícola por persona son del $10 \%$ en la región centro, y el $12 \%$ en las regiones del norte y sur.

4) Respecto del análisis electoral (Mapa 8), al igual que en Ucrania el expresidente de la anterior RSS también lo fue de la nueva república independiente. De este modo, Snegur consiguió la presidencia en 1991, siendo el único candidato. En las elecciones presidenciales de 1996 hubo de medirse con otros rivales. Snegur consiguió los mayores apoyos en Criuleni (más del $60 \%$ ) y en otros distritos del centro y sureste como Rezina, Dubasari, Causeni, Stefan Voda, Nisporeni, Straseni o Ialoveni. Voronin, el candidato del partido comunista logró sus mayores proporciones de voto en distritos rurales como Drochia, Cahul, Taraclia o en Gagauzia (que también coinciden con la presencia de minorías). En la segunda vuelta, el ganador Lucinschi, independiente aunque vinculado al partido agrario, venció a Snegur y logró mayores apoyos en las zonas rurales votantes de Voronin, como los distritos del norte y sur, llegando en Gagauzia a más del 90 \%. En las legislativas de 1998 se vuelve a producir esta dualidad: el Partido Comunista ganó las elecciones, consiguiendo sus mejores resultados en todos los distritos de la región norte y en el sur. Sin embargo, se consensuó una mayoría formada por una Coalición Democrática de partidos cristianos, ecologistas, aperturistas y nacionalistas, que lograron sus mejores resultados en el centro del país. En las elecciones de 2005, el esquema de voto se repite: los comunistas ganan con facilidad en Gagauzia y los distritos del norte, mientras que el Bloque Democrático de Moldavia lo hace en el centro del país. En 2010, el Partido Comunista volvió a ganar las elecciones, revalidando mayorías en sus feudos en Gagauzia, Ocnita, Taraclia o Balti. La alianza para la integración europea consiguió sus mejores resultados en el centro del país. En las últimas elecciones presidenciales de 2016, Dodon (del Partido Socialista de Moldavia, que desplaza al Comunista), y de ideología prorrusa cosechó los mayores votos en Gagauzia (casi el $100 \%$ ) y en los distritos del norte, por encima del $80 \%$. Venció a Sandu, proeuropea, del Partido Acción y Solidaridad, núcleo del Partido Liberal Democrático de Moldavia. Sandu consiguió éxito en el centro del país, llegando a más del $95 \%$ en distritos como Ialoveni, o ganando en la capital Chisinau.

Es de destacar que los datos solo se encuentran disponibles para el territorio controlado por la República de Moldavia, no hay datos para Transnistria. Esta región al otro lado del Dniéster se caracterizaba por una predominancia de rusos étnicos, aunque también se contaban ucranianos. La lengua oficial es el ruso; la controversia en torno al rumano llegó a su punto álgido en 2004 cuando se cerraron 
escuelas que impartían en ese idioma y alfabeto latino (prefiere optarse por el rumano en cirílico, no se reconocen los títulos en latino). En cuanto a la economía, Transnistria fue la parte de Moldavia donde se realizó, en tiempos de la URSS, una mayor inversión en industria (siderúrgica, energética, textil) llegando a representar el $40 \%$ de la industria de Moldavia y el $90 \%$ de la producción eléctrica (Mackinlay y Cross, 2003, p.135).

Mapa 8. Resultados electorales en Moldavia: 1998, 2005, 2010 y 2016

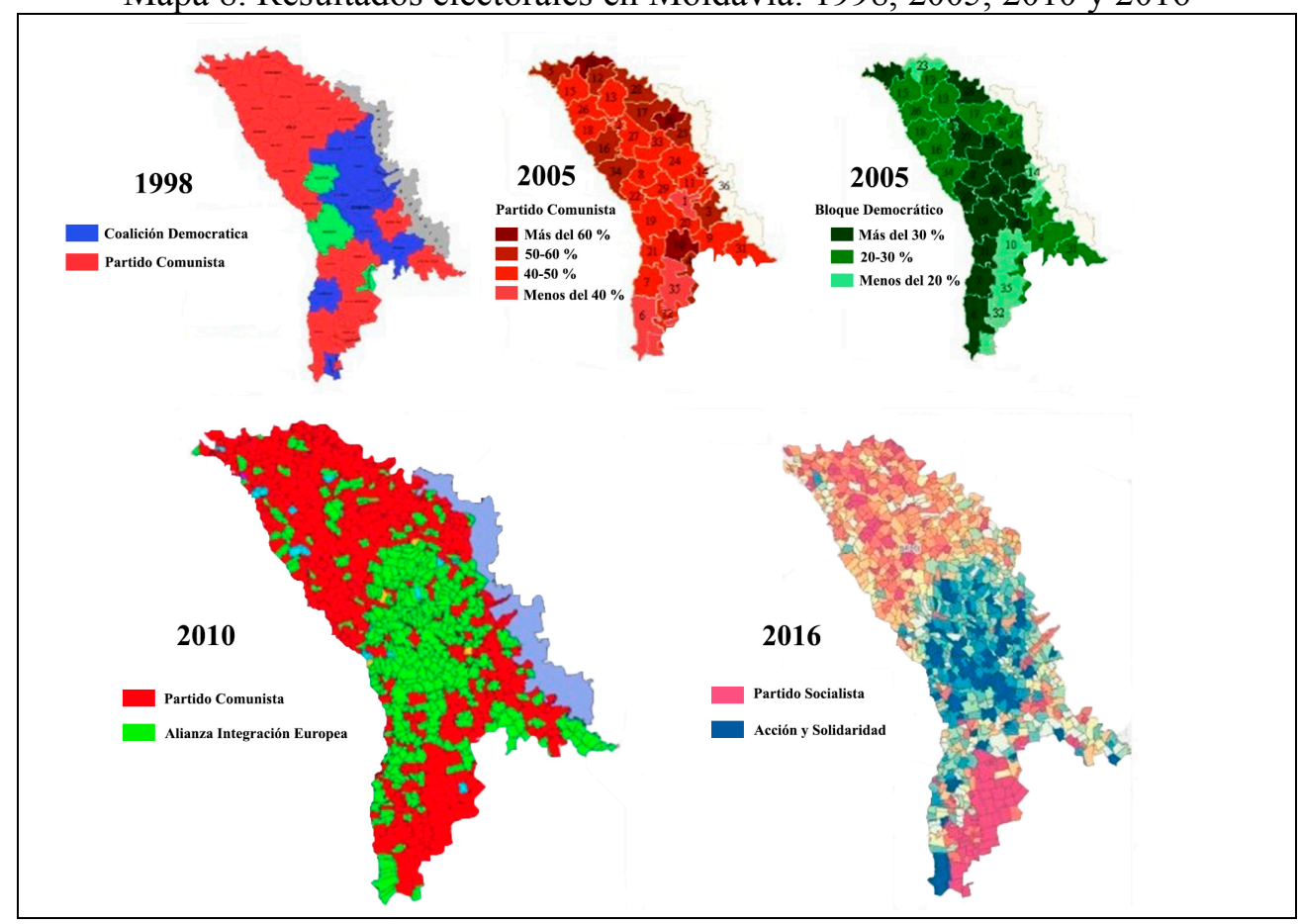

Fuente: www.electoralgeography.com, con datos de Comisia Electorala Centrala a Republicii Moldova.

La complejidad moldava se visualiza en determinados aspectos. El conflicto congelado de Transnistria ha dado lugar a un Estado independiente de facto. Se correspondía con la parte más industrializada de Moldavia, y lugar de residencia de rusos, donde el ruso es el único idioma plausible. Gagauzia, habitada por los gagauzos, es una entidad eminentemente agraria, donde los idiomas gagauzo y ruso son los más empleados. Otras minorías étnicas rusas, rusoparlantes y con mayor vocación agraria residen en el norte del país. En general, estos territorios poblados por minorías, con idiomas usados distintos del rumano (gagauzos y búlgaros prefieren el ruso como segunda lengua), esencialmente agrícolas y con un nivel de vida más bajo optan por votar partidos cercanos a la órbita de Moscú. Por su parte, el centro del país, donde el uso del rumano es común, con salarios algo más altos y con un porcentaje agrario más reducido (aunque se recalca el contexto de economía fuertemente precarizada y dependiente del sector primario), suelen optar por partidos proeuropeos y nacionalistas moldavos. 


\section{6. ¿Y dentro de la UE y la OTAN? Fronteras ocultas en Letonia}

Letonia no se encuentra dentro de la "zona gris", ya que su pertenencia a la Unión Europea y OTAN desde 2004 garantiza, en principio, su integridad territorial. Una agresión a un Estado miembro de estas alianzas supondría una contestación directa, la cual dista mucho de poder producirse. Sin embargo, resulta interesante estudiar un caso en el que las diferencias internas pueden ser aprovechadas para generar inestabilidad en el gobierno de un país de la UE. El pueblo báltico de los letones estuvo vinculado a otras regiones, como su pertenencia a la liga hanseática, o al dominio polaco-lituano, sueco y ruso. Independientes por un breve periodo tras la I Guerra Mundial, fue ocupada por los ejércitos soviético y nazi, hasta que tras la II Guerra Mundial se constató el dominio soviético y su integración como una RSS en la URSS. Durante este periodo, Letonia sufrió una intensa rusificación, en la que la llegada de rusos para trabajar en astilleros en Riga, administración, militares y otras industrias hizo casi comparable la proporción entre letones y rusos (a la misma vez que se deportaba a letones a otras regiones). En 1991, Letonia, por medio de la "Revolución Cantada", accedió a su independencia junto a las otras dos repúblicas bálticas. Desde entonces, su política ha girado en torno a la órbita europea y antirrusa. Un ejemplo de ello es la situación de los ciudadanos alien, identificados como "no ciudadanos", habitantes con pasaporte de la URSS que no tienen derechos políticos y no pueden acceder a puestos de trabajo en la Administración (por supuesto, tampoco en las fuerzas armadas ni policía) (González, 2018, p.57). Estos sumaban en 2015 la cifra de 252.195 personas, y para acceder a la ciudadanía letona han de superar un examen de idioma letón. El Mapa 9 muestra las fronteras internas en Letonia, que resultan de:

1) Los letones son más del $75 \%$ de la población en los municipios del oeste (Curlandia) y los del centro-este (Vidzeme y parte de Zemgale). Los rusos son una amplia minoría en el sureste, en la región de Latgale (donde son mayoría en Daugavpils, $54 \%$, o en Rezekne, donde son $45-45 \%$ letones y rusos), así como en la capital Riga (38\%). Dos terceras partes de los catalogados como "no ciudadanos" o "alien" son rusos, y se aumenta a más del $75 \%$ si se suman rusos y belarusos (Oleinika, 2015).

2) Si bien la única lengua oficial es el letón $-y$ las políticas lingüísticas letonas han sido duramente criticadas por la UE_-, el ruso es hablado por la mayoría de la población en Latgale, en municipios como Daugavpils, Kraslava, Rezekne, e incluso en Riga. En 2012 se votó en referéndum la oficialidad del ruso como segundo idioma, cuyo resultado fue negativo (más del $90 \%$ en contra en la mayor parte del país). Los porcentajes más a favor se encontraron en Zilupe (90\%), Daugavpils (85 $\%)$, Kraslava (61 \%), Ludza (60\%), Rezekne (60\%), Dagda (52\%), todas en Latgale, y en Riga llegó al 36 \% (Centrala statistikas parvalde, 2019).

3) El desempleo es mayor en el este del país (más del $25 \%$ en Rezekne) y más del $20 \%$ en Kraslava, Balvi o Ludza, por lo general, el doble que en las demás regiones del país (Akadēmiskās Informācijas Centrs, 2019). Los salarios más altos se consiguen en torno a la capital y en Ventspils, Curlandia (más de $1000 €$ mensua- 
les), mientras que en el suroeste y sobre todo en Latgale apenas se sitúan entre los 500 y $600 €$ mensuales (Centrala statistikas parvalde, 2019).

Mapa 9. Fronteras étnicas, lingüísticas y económicas en Letonia

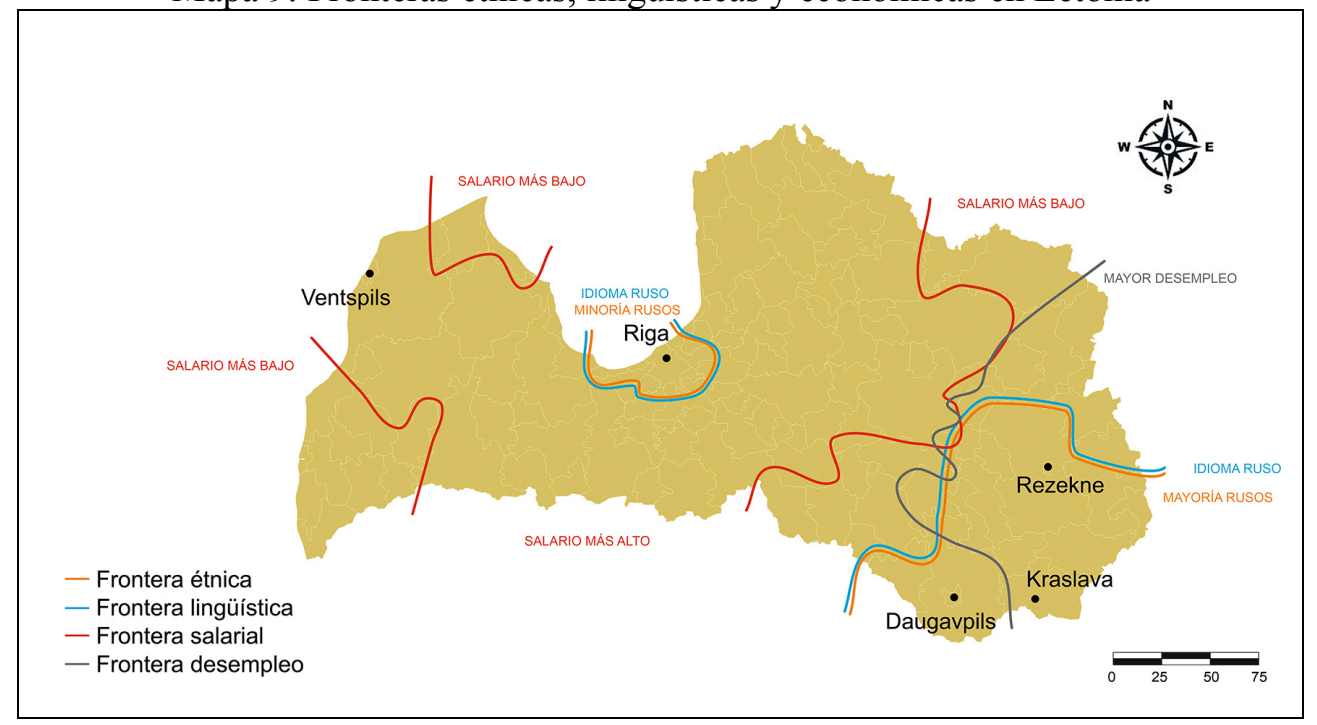

Fuente: elaboración propia.

4) Realizando un repaso por los resultados electorales (Mapa 10), ya en 1991 se aprecia una división. En el referéndum de independencia, más del $90 \%$ en los distritos de Curlandia votó a favor; mientras que en las ciudades de Daugavpils y Rezekne fue inferior al $50 \%$. En 1998, se realizó un referéndum para derogar o no la nueva Ley de ciudadanía, que proponía mejoras para facilitar el acceso a la ciudadanía letona de los considerados alien. Ganó el no, sobre todo en Latgale, con más del $80 \%$. En el referéndum de 2003 sobre la adhesión a la UE, el sí ganó holgadamente en todas las provincias salvo en Latgale, donde se situó incluso por debajo del $40 \%$ en Daugavpils. En cuanto a elecciones, las de 2002 ya arrojan resultados diferenciados: el partido Nueva Era, proeuropeo, gana en el centro del país, con máximos del $33 \%$ en el distrito de Riga y en Tukums, y $31 \%$ en la ciudad de Ventspils, Cesis y en Limbazi; mientras que apenas lograba un $5 \%$ en Daugavpils, o un $8 \%$ en Kraslava y Rezekne. Por su parte, el partido "Para los Derechos Humanos en una Letonia Unida" ganaba en Kraslava con el $51 \%$, Daugavpils con el $47 \%$ o Ludza $46 \%$; mientras que en Liepaja era del 1,6\% o Talsi del 1,8 \%. Las elecciones europeas de 2004 volvieron a mostrar el voto de Latgale hacia este partido prominorías; al igual que las parlamentarias de 2009, donde concurre con el nombre de Centro de Armonía. Este partido ha sido el ganador de las elecciones en 2011, 2014 y 2018, aunque nunca ha podido formar gobierno debido a las alianzas establecidas entre los demás partidos, y suele conseguir sus mejores resultados en Daugavpils (60\%), Zilupes (51\%), Rezekne (50\%), y también en Riga (36\%), según datos de 2014. 
Mapa 10. Resultados electorales en Letonia: 2002, 2003, 2009, 2011, 2014 y 2018

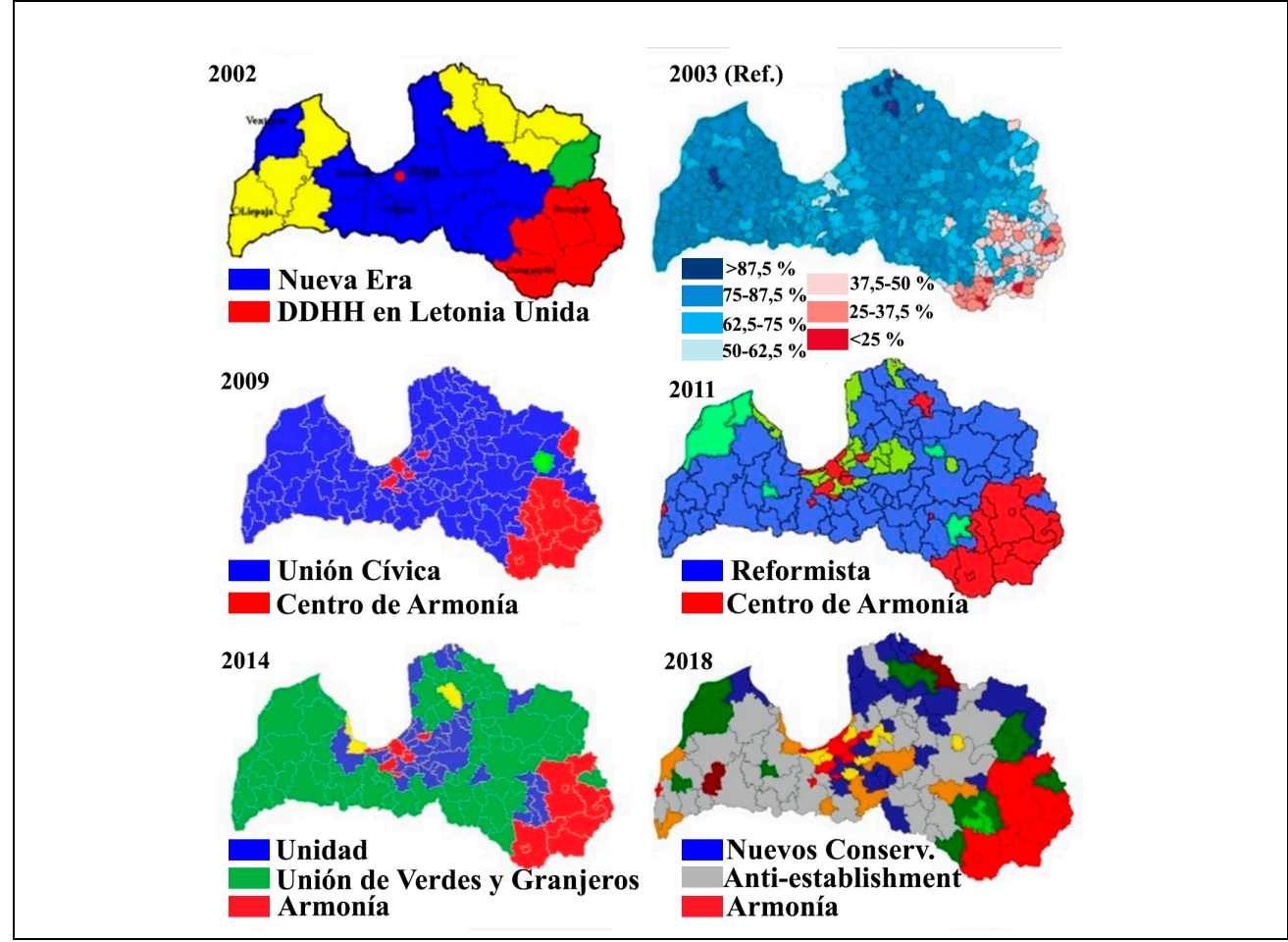

Fuente: www.electoralgeography.com, con datos de Centrālā vēlēšanu komisija.

El caso de Letonia muestra una fuerte división concentrada en Latgale, en el sureste del país. Aquí viven rusos étnicos, que emplean el ruso como idioma cotidiano, y que sufren una situación económica peor que el resto de letones, con mayor desempleo y salarios más bajos, con un voto político fuertemente regionalizado. Además, se ha de tener en cuenta que los "no ciudadanos" son en su mayoría rusos, y estos no han podido votar. Las políticas lingüísticas y de ciudadanía letonas pueden llevar a Latgale a cierto desencanto con el conjunto letón, máxime cuando su partido ha sido el más votado en varias ocasiones, pero sin oportunidad de ejercer el gobierno. En este sentido, es de destacar la declaración de independencia de Latgale en 2015, simbólica y virtual, aunque una provocación. Como señala González (2018, p.58), ciertas campañas informativas pueden provocar tensiones hasta la fecha congeladas, para desestabilizar el país. Aunque la probabilidad de rebelión es baja, ya que la ciudadanía europea otorga ciertas ventajas frente a los demás rusos no comunitarios, como apunta Esteban (2016, p.1213), los rusos en Letonia podrían seguir el ejemplo de los rusos en Ucrania.

\section{Conclusiones}

La zona gris está definida por una ambigüedad intencionada y por un espectro de la paz donde esta se encuentra cuestionada debido a conflictos geopolíticos propicia- 
dos por un agente externo (superpotencia o potencia regional). En este sentido, Rusia intenta controlar su vecindario y la ampliación de las fronteras de la OTAN en él es percibida como una amenaza en su influencia. En este artículo se ha presentado el espacio exsoviético como la zona gris europea, un área que Rusia parece intentar desestabilizar para frenar el expansionismo europeo y que derivó en conflicto abierto en Ucrania tras la crisis de 2013. Es por ello que se ha estudiado la división de Ucrania con base en un esquema de trabajo que analiza las diferencias étnicas, lingüísticas, económicas y electorales. El resultado es la coincidencia de realidades diferentes, de fronteras ocultas que salen a la luz en situaciones de desestabilización. Se ha comprobado que, a grandes rasgos, Ucrania estaba dividida en población ucraniana $v s$. rusa; lengua ucraniana vs. lengua rusa; economía agraria $v s$. economía industrial; salarios bajos $v s$. salarios más altos; voto a partidos proeuropeos $v s$. voto a partidos prorrusos. Todas estas diferentes líneas superpuestas coinciden espacialmente (cinco de cinco) formando una frontera oculta, que dio lugar al conflicto abierto en 2013-2014.

Este modelo de trabajo se ha extrapolado a otros tres casos en los que se averiguan las fronteras ocultas a diversos niveles, que superpuestos todos ellos pueden dar lugar a una fracturación que las visibilice en situaciones de crisis. En el caso de Belarús, las distintas diferencias a nivel étnico, lingüístico, económico y electoral no coinciden totalmente, por lo cual se podría decir que no existe una frontera oculta clara que divida al país en dos. Únicamente se aprecia que en el oeste del país es donde se asienta la minoría polaca y que es también en el oeste donde predomina el idioma belaruso, y que es parte de un área eminentemente rural mucho más extensa y que no es exclusiva característica del oeste. La frontera salarial está condicionada por la división rural/urbana y no define una región concreta. La única elección libre de 1994 arrojó mayor apoyo a Paznyak, por lo que se podría decir que superpuestas apenas coinciden 2 fronteras claras y otra algo más difusa, de las 5 estudiadas.

Dejando a un lado Transnistria, Moldavia está condicionada por las minorías residentes en el sur (Gagauzia) y norte (rusos y ucranianos), territorios donde el moldavo es menos (o escasamente) utilizado y la economía depende esencialmente de la agricultura, si bien la economía de todo el país está prácticamente basada en el sector agrícola y las diferencias son muy sutiles. Sí es cierto que el voto a partidos proeuropeos es más fuerte en el centro del país, y que los candidatos prorrusos obtienen sus mejores resultados en Gagauzia y los distritos del norte. En el norte coinciden 3 fronteras claras y otra algo más difusa; el sur de Moldavia, con la minoría gagauza constituida en su propia República Autónoma sí coinciden las cinco fronteras analizadas, con lo cual se puede extraer que la realidad gagauza es bien diferente de la del centro de Moldavia: minoría étnica, lengua diferente, economía más agraria, salarios más bajos, voto prorruso. Se identifica, por lo tanto, una frontera oculta que Moldavia debe considerar a la hora de determinar su rumbo político.

Letonia es un país de la UE y OTAN y, por tanto, no se categoriza como "zona gris", pero sí que resulta de interés debido a que alberga una importante minoría de rusos, potencia que parece intentar la desestabilización de su vecindario como fuerza para ejercer su influencia. La injerencia rusa puede ser un factor clave en el devenir político de los Estados bálticos, ya que puede contribuir a la agitación social y a posibles rebeliones. Entre los bálticos, el caso letón cobra mayor relevancia puesto que es una extensa región, Latgale, la que acumula las cinco diferencias 
estudiadas, que la separa del resto del país. Aquí se encuentran una mayor proporción de rusos, se habla ruso, hay mayor desempleo, salarios bajos y voto a partidos prorrusos. Letonia debe paliar estas fronteras para prevenir posibles conflictos sociales y políticos en Latgale, que cuestionen el sistema actual o la pertenencia a UE y OTAN y que puedan ser aprovechados por la vecina Rusia en su interés. Es preciso recordar que, aunque no exista un movimiento independentista en Latgale, tampoco lo existía en el este de Ucrania, y la RPL y RPD nacieron en un contexto de crisis en la zona gris, visibilizando las fronteras ocultas en el interior del país.

Entre las conclusiones extraídas, se destaca la importancia de las minorías (motivadas por un pasado histórico o por valores culturales propios), las políticas lingüísticas (que pueden ser discriminatorias respecto de minorías), la distribución de la riqueza (materializada en la ocupación y el salario), y todo ello, reflejado en una división electoral que, si es prolongada en el tiempo, puede ser un target con el que movilizar a la población civil.

Por último, se hace referencia a que, si se añaden estrategias de desestabilización en una zona gris, puede dar lugar a una guerra híbrida. Una simple frontera étnica, lingüística, económica o política no motiva una insurgencia, pero a mayor concurrencia de estas fronteras ocultas, mayor será la división social en el territorio mediante situaciones de desestabilización en una zona gris.

\section{Agradecimientos}

Quisiera agradecer a Rubén Camilo Lois González (Universidade de Santiago de Compostela) y a los revisores las valiosas consideraciones que han ayudado a la mejora de este artículo.

\section{Referencias}

Ademmer, E., Delcour, L., y Wolczuk, K. (2016). Beyond the geopolitics: exploring the impact of the EU and Russia in the contested neighborhood. Eurasian Geography and Economics, 57(1), 1-18.

Allison, R. (2014). Russian "deniable" intervention in Ukraine: how and why Russia broke the rules. International Affairs, 90(6), 1255-1297.

Ancel, J. (2016 [1936]). La geografía de las fronteras: el método. Geopolítica(s), 7(1), 131142.

Baqués, J. (2015). El papel de Rusia en el conflicto de Ucrania: ¿la guerra híbrida de las grandes potencias? Revista de Estudios en Seguridad Internacional, 1(1), 41-60.

Baqués, J. (2017). Hacia una definición del concepto de Gray Zone (GZ). Documento de Investigación. Instituto Español de Estudios Estratégicos. 02/2017. 23 de marzo de 2017. Pp 1045-1076.

Beyer, J., y Wolff, S. (2016). Linkage and leverage effects on Moldova's Transnistria problem. East European Politics, 32(3), 335-354.

Brands, H. (2016). Paradoxes of the Gray Zone. Foreign Policy Research Institute E-Notes, 5 de febrero. Recuperado de https://www.fpri.org/article/2016/02/paradoxes-gray-zone/

Byllk, L. (2018). Orígenes del conflicto ucraniano. Aequitas, (12), 158-177. 
Casas, M., Cobarrubias, S., y Pickles, J. (2011). Stretching borders beyond sovereign territories? Mapping EU and Spain's border externalization policies. Geopolitica(s), 2(1), 71-90.

Claudín, C. (2015). Europa oriental en 2015: a la hora de Moscú. Anuario Internacional CIDOB 2015 (pp.91-98). Barcelona: CIDOB.

Englund, S. H. (2019). A dangerous middle-ground: terrorists, counter-terrorists, and grayzone conflict. Global Affairs, 5(4-5), 389-404. DOI: 10.1080/23340460.2019.1711438

Esteban, A. (2016). OTAN: el oso y las hienas. Instituto Español de Estudios Estratégicos, Documento Marco 11/2016, de 5 de julio de 2016. Pp.1201-1233.

Ezcurra, R., y Rodríguez-Pose, A. (2017). Does ethnic segregation matter for spatial inequality? Journal of Economic Geography, 17(6), 1149-1178. DOI: 10.1093/jeg/lbx007

González, A. (2018). Efectos de la guerra de Ucrania en las Repúblicas Bálticas. . Instituto Español de Estudios Estratégicos, Documento de Análisis 26/2018. 11 de julio de 2018. Pp.44-62.

Hartshorne, R. (1937). The Polish Corridor. Journal of Geography, 36(1), 161-176.

Hoffman, F. G. (2016). The contemporary spectrum of conflict: protracted, gray zone, ambiguous, and hybrid models of war. En 2016 Index of U.S. Military Strength (pp.25-36). The Heritage Foundation. Recuperado de https://www.heritage.org/sites/default/files/201908/2016_Index_of_US_Military_Strength_ESSAYS_ALL.pdf

Huntington, S. P. (1996). The clash of civilizations and the remaking of world order. New York: Simon \& Schuster.

Jordán, J. (2018). El conflicto internacional en la zona gris: una propuesta teórica desde la perspectiva del realismo ofensivo. Revista Española de Ciencia Política, (48), 129-151.

Jovaní, C. (2014). El nacionalismo ruso y sus visiones geopolíticas de Eurasia. Geopoliti$c a(s), 5(2), 165-206$.

Kapusta, P. (2015). The Gray Zone. Special Warfare Magazine, October-December, 19-25. Recuperado de https://www.soc.mil/SWCS/SWmag/archive/SW2804/GrayZone.pdf

Korosteleva, E. A. (2016). Belarus between the European Union and the Eurasian Economic Union: a national values survey 2016. Bruselas: ODB Brussels / Swedish International Development Agency / Global Europe Centre University of Kent.

Kuzio, T. (2005). From Kuchma to Yushchenko Ukraine's 2004 Presidential Elections and the Orange Revolution. Problems of Post Communism, 52(2), 29-44.

Lanoszka, A. (2016). Russian hybrid warfare and extended deterrence in Eastern Europe. International Affairs, 92(1), 175-195.

López, J. A. (2018). El vecindario oriental de la Unión Europea y los conflictos postsoviéticos. Revista de Estudios en Seguridad Internacional, 4(2), 49-66.

López Trigal, L. (2011). Comentario: "Las leyes del crecimiento espacial de los Estados" en el contexto del determinismo geográfico ratzeliano. Geopolitica(s), 2(1), 157-163.

Mackinlay, J., y Cross, P. (2003). Regional Peacekeepers: The Paradox of Russian Peacekeeping. Tokio: United Nations University Press.

Mìnfìn (Мінфін). (2016). Середня місячна зарплата по регіонах України в 2016 р. (грн.). Recuperado de https://index.minfin.com.ua/ua/labour/salary/average/2016

Minghi, J. V. (2018 [1963]). Los estudios de frontera en Geografía Política. Geopolítica(s), 9(2), 291-325.

Morales, S. (2015). Herramientas de modificación y ampliación del área de influencia estratégica de Rusia. Revista de Estudios en Seguridad Internacional, 1(2), 85-107. 
Morales, J. (2018a). ¿Una nueva Guerra Fría? La militarización del discurso entre Rusia y Occidente. Anuario CEIPAZ 2017-2018 (pp. 141-151). Madrid: CEIPAZ.

Morales, J. (2018b). Seguridad ontológica y percepciones de amenaza: Rusia ante la ampliación de la OTAN. Revista de Estudios en Seguridad Internacional, 4(2), 1-15.

Morris, L. J. (2019). Gray zone challenges in the East and South China sea. The Maritime Issues, 7 de enero. Recuperado de http://www.maritimeissues.com/politics/gray-zonetactics-and-their-challenge-to-maritime-security-in-the-east-and-south-china-sea.html

Nohlen, D., y Stöver, P. (Eds.). (2010). Elections in Europe: A Data Handbook. BadenBaden, Alemania: Ed. Nomos.

Oleinika, J. (2015). Non-citizens - the Aliens at Home. Examining the Place of the Russian Non-citizens in Latvia. Dissertation, School of Social, Historical and Literary Studies, University of Portsmouth, Reino Unido.

Rodríguez-Pose, A. (2018). The revenge of the places that don't matter (and what to do about it). Cambridge Journal of Regions, Economy and Society, 11(1), 189-209. DOI: 10.1093/cjres/rsx024

Ruppert, K., y Schaffer, F. (1979). La polémica de la Geografía Social en Alemania (I): sobre la concepción de la Geografía Social. GEOCrítica, IV(21). Recuperado de http://www.ub.edu/geocrit/geo21.htm

Sahm, A. (2010). Belarus. En D. Nohlen y P. Stöver (Eds.), Elections in Europe: A Data Handbook (pp.233-268). Baden-Baden, Alemania: Ed. Nomos.

Schadlow, N. (2014). Peace and War: The Space Between. War on the Rocks, 18 de agosto. Recuperado de https://warontherocks.com/2014/08/peace-and-war-the-space-between/

The Washington Post (2014) This is the one map you need to understand Ukraine's crisis. The Washington Post, 24 de enero. Recuperado de https://www.washingtonpost.com/news/worldviews/wp/2014/01/24/this-is-the-onemap-you-need-to-understand-ukraines-crisis/?noredirect $=$ on\&utm_term $=.84 \mathrm{a} 0 \mathrm{cc} 2 \mathrm{ad} 174$

US Department of Defense. (2010). Quadrennial Defense Review Report. Washington D.C.: Department of Defence.

Wirtz, J. J. (2017). Life in the "gray zone": observations for contemporary strategists. Defense and Security Analysis, 33(2), 106-114.

\section{Sitios de internet}

Akadēmiskās Informācijas Centrs (2019) (Centro de Información Académica): www.aic.lv

Deržavna služba statistiki ukraïni (Державна служба статистики україни). (2001). Всеукраӥнський перепис населення. (State Statistics Committee of Ukraine: All Ukrainian population census 2001): www.ukrcensus.gov.ua

Centrala statistikas parvalde. (2019). (Oficina Central de Estadística de Letonia): www.csb.gov.lv

Centrālā vēlēšanu komisija (Comisión Central de Elecciones de Letonia): www.cvk.lv

Central'noï viborčoï komìsiï (Центральної виборчої комісії). (2019) (Comisión Central Electoral de Ucrania): www.cvk.gov.ua

Comisia Electorala Centrala a Republicii Moldova (Comisión Central Electoral de Moldavia): www.a.cec.md

Electoral Geography 2.0: www.electoralgeography.com 
Nacional'nыj statističeskij komitet Respubliki Belarus' (Национальный статистический комитет Республики Беларусь). (2019). Comité Nacional de Estadística de la República de Belarús: www.belstat.gov.by

Statistica Moldovei (2019) Biroul National de Statistica al Republicii Moldova - Oficina Nacional de Estadística de Moldavia: www.statistica.gov.md 